\author{
A Thesis \\ presented to \\ the Faculty of California Polytechnic State University, \\ San Luis Obispo
}

In Partial Fulfillment

of the Requirements for the Degree

Master of Science in Agriculture, with Specialization in:

Food Science and Nutrition

by

Megan M. Bishop

March 2012 


\section{(C) 2012}

Megan M. Bishop

\section{ALL RIGHTS RESERVED}




\section{COMMITTEE MEMBERSHIP}

TITLE:

VITAMIN D SUB-SET ANALYSIS FROM THE FLASH STUDY- A LONGITUDINAL COLLEGE STUDENT COHORT

AUTHOR:

Megan M. Bishop

DATE SUBMITTED:

March 2012

COMMITTEE CHAIR: Laura Hall, PhD, RD

COMMITTEE MEMBER: Ann Yelmokas McDermott, PhD, MS, LDN

COMMITTEE MEMBER: Aydin Nazmi, PhD 


\section{ABSTRACT \\ Vitamin D Sub-Set Analysis from the Flash Study- A Longitudinal College Student Cohort Megan M. Bishop}

Vitamin $D$ is important to the health of college students. The objective of our study was to measure sun exposure, skin pigmentation, vitamin D intake, and serum 25-hydroxyvitamin $\mathrm{D}(25[\mathrm{OH}] \mathrm{D})$ in a subset of participants from The Following the Longitudinal Aspects of Student Health (FLASH) Study to determine the best predictors of 25(OH)D status. Participants were college-aged freshman who had their blood drawn in spring (Visit 1) and fall 2010 (Visit 2) at California Polytechnic State University (Cal Poly), San Luis Obispo, CA. $\left(35.3^{\circ} \mathrm{N}\right)$. Vitamin $D$ intake was measured using a 28-day food frequency recall questionnaire (specific to vitamin $D$ foods and supplements) while questions specific to the frequency of milk and fish intake were accessed from the FLASH questionnaire. Sun exposure was measured using a 28-day recall questionnaire (time in sun and sun exposure index [SEI]) and questions (frequency of weekday/ weekend exposure) from the FLASH questionnaire. Skin pigmentation was measured using a reflectance spectrophotometer. Serum 25(OH)D was measured at a local pathology lab as measured by an IDS-iSYS. Means (SD) were as follows $(n=40)$ : reflectance of the forehead was 61 (3.5) L* (Lightness) for Visit 1 and 61 (4.3) L* for Visit 2. Vitamin D intake was 308 (234) IU for Visit 1 and 316 (257) IU for Visit 2. Time outside was 81 (44) mins for Visit 1 and 76 (39) mins for Visit 2. Serum 25(OH)D was $85(24) \mathrm{nmol} / \mathrm{L}$ for Visit 1 and $113(28)$ $\mathrm{nmol} / \mathrm{L}$ in Visit 2 which was significantly higher $(\mathrm{p}<0.0001)$. The SEI was 53 (38) body surface area (BSA) exposed $\left(\mathrm{m}^{2}\right) \times$ mins for Visit 1 and $55(34) \mathrm{m}^{2} \times$ mins Visit 2. Although $90 \%$ of participants in Visit 1 and $88 \%$ in Visit 2 were below the RDA guidelines for vitamin $D$ intake (600 IU/day), $5 \%$ of participants in Visit 1 and none in Visit 2 had serum 25(OH)D serum levels $<50 \mathrm{nmol} / \mathrm{L}$ (the recommended level of sufficiency for bone health), demonstrating the importance of sun exposure to vitamin D status in these college students. To determine the strongest predictors of status we used regression analysis to predict serum $25(\mathrm{OH}) \mathrm{D}$ with skin reflectance, vitamin $\mathrm{D}$ intake, and sun exposure. We found that weekend sun exposure, fish intake, and forehead skin reflectance were the strongest predictors of serum $25(\mathrm{OH}) \mathrm{D}\left(\mathrm{R}^{2}=0.50, \mathrm{p}=0.0010\right)$ demonstrating that simple questionnaires can help to predict serum $25(\mathrm{OH}) \mathrm{D}$ status. 


\section{ACKNOWLEDGMENTS}

I would like to thank numerous people who helped me attain my master's degree. Foremost, Dr. Laura Hall has enthusiastically worked with me for the past two and a half years. She personally developed my critical thinking skills and taught me how to accurately conduct a research project. Dr. Laura Hall has been a continual source of guidance, support and motivation as I have pursued my graduate degree. I would also like to thank my collaborators, Dr. Ann McDermott and Aydin Nazmi for adding their expertise and insight to my study. In conjunction to my academic advisors, I would like to thank my parents, Alan and Cindy Bishop, for their enduring love and confidence. I would also like to thank my two sisters, Ahna and Kendra, as well as my close friends for their support. 


\section{TABLE OF CONTENTS}

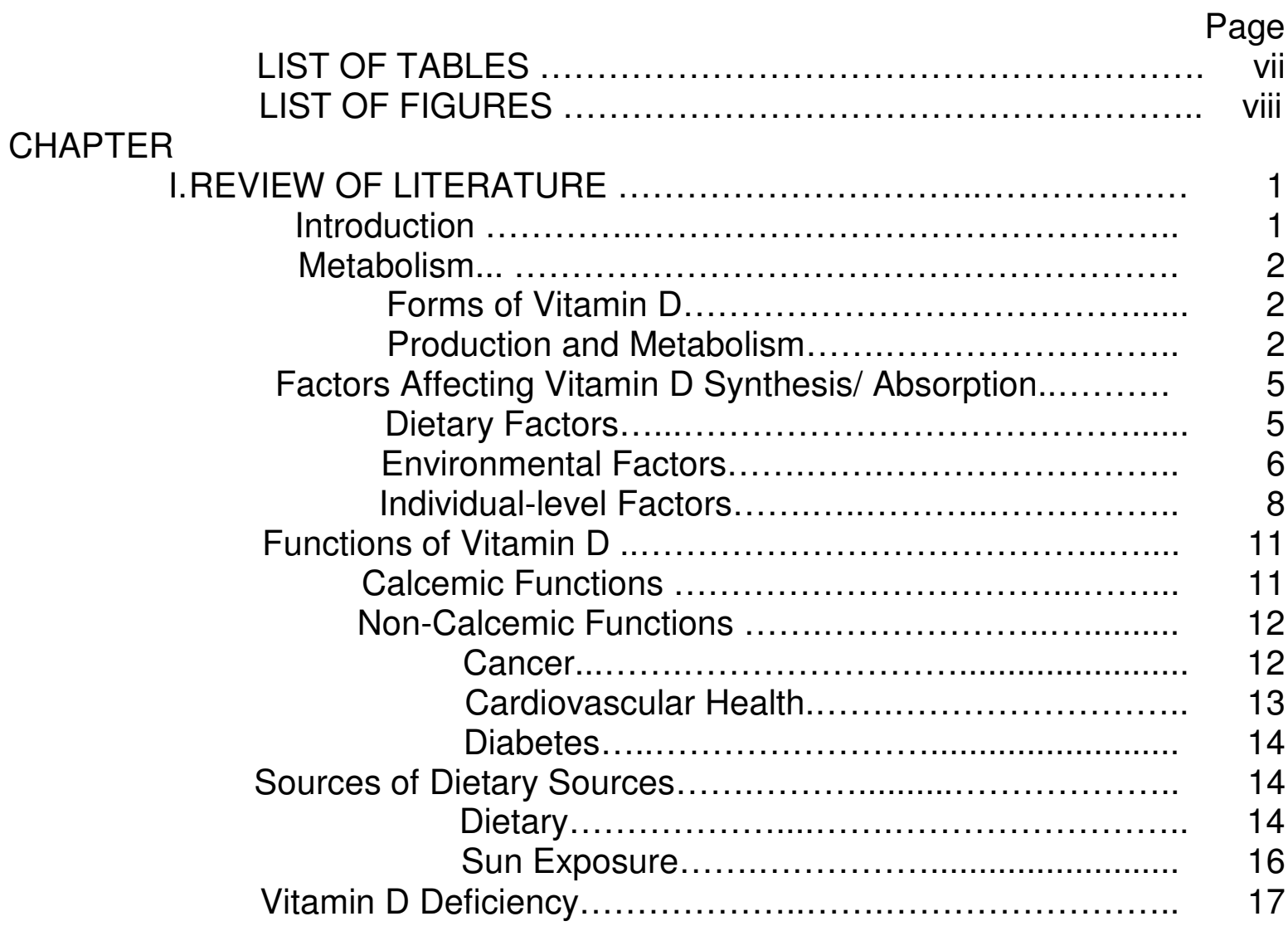

Prevalence of Vitamin D deficiency in the United States . 17 Vitamin D Intakes................................................. 20

Consequences of Deficiency................................ 21

Rickets....................................... 21

Osteoporosis...................................... 23

Vitamin D Intake Recommendations.......................... 25

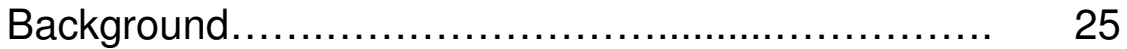

Setting the New RDA.................................... 26

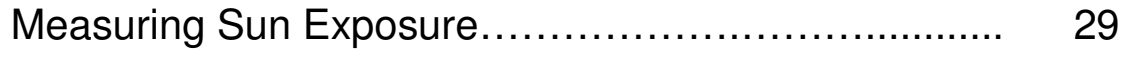


Conclusion............................................................. 31

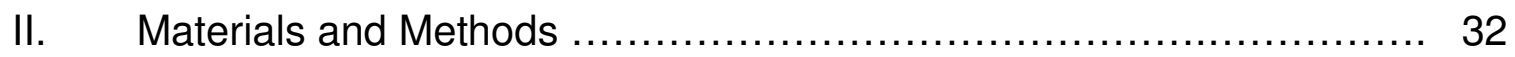

Study Design of FLASH Study ............................... 32

Study Design of Vitamin D Subset Study ...................... 32

Participants............................................... 33

Study Hypothesis and Specific Objectives.................... 34

Serum 25(OH)D............................................. 34

Sun Exposure Assessment................................ 35

Dietary Vitamin D Assessment ............................ 37

Skin Reflectance Assessment ........................... 38

Statistical Methods............................................ 38

III. Results ........................................................ 40

Characteristics of Study Participants........................ 40

Sociodemographic Data..................................... 41

Serum 25(OH)D Measurements............................ 43

Sun Exposure.................................................. 44

FLASH Sun Exposure Results .............................. 44

28-day Sun Exposure Recall: Time in the sun................. 47

Sun Exposure (SEI) ........................................ 47

Vitamin D Intake............................................... 49

FLASH Dietary Results..................................... 49

Vitamin D Specific Food Frequency Questionnaire............. 50

Skin Reflectance (Pigmentation) Measurements.................. 51

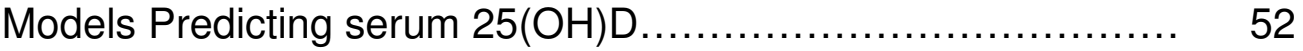

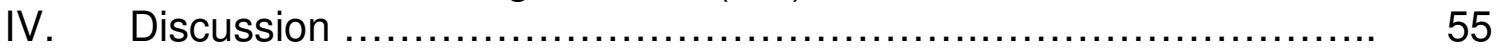

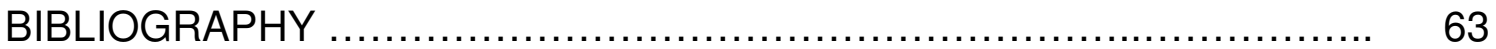

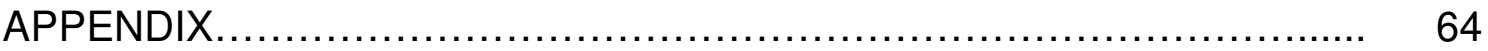

A. Sun Exposure Form

B. Food Frequency Questionnaire- Example

C. Food Frequency Questionnaire- Template

D. FLASH Study: Sun Exposure Questions 


\section{TABLE}

\section{LIST OF TABLES}

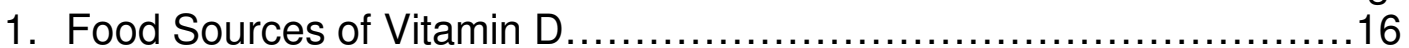

2. National Center for Health Statistics percentile data for serum

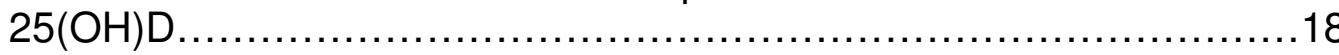

3. T-scores indicating bone mineral density diagnosis...................25

4. Vitamin D Dietary Reference Intakes by Life Stage (amount/day).......29

5. Characteristics of Study Participants along with Vitamin D Intake, Time Spent in the Sun, Sun Exposure Index, Serum 25(OH)D and Forehead Skin Pigmentation (mean \pm SD)

6. Sociodemographic Data From FLASH Questionnaire....

7. Sun Exposure and Sunscreen Use from FLASH Questionnaire [percent $(n)]$

8. Dietary Information Related to Vitamin D Intake from FLASH Questionnaire [percent $(n)]$

9. Models Comparing Different Measures of Sun Exposure, Diet and Skin Pigment to Predict Vitamin Status. 
1. Vitamin D Production and Metabolism …............................... 5

2. $37^{\text {th }}$ Parallel Latitude of the United States................................... 8

3. Age and Serum-adjusted prevalence at risk of deficiency and Inadequacy among persons aged 12 years and over. United States,

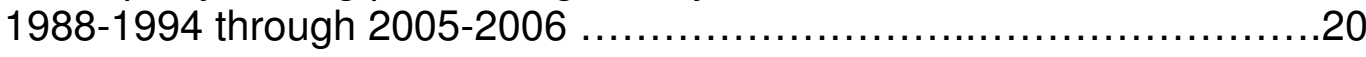

4. Incidence of Osteoporosis Fractures Worldwide ...........................24

5. Visit 1 and Visit 2 data collection from Vitamin D assessment and

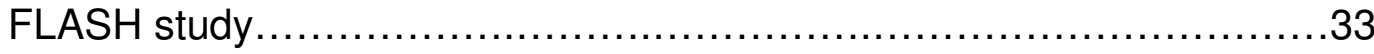

6. Sun Exposure Key was used by participants in study to document

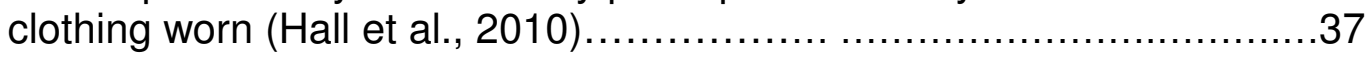

7. Individual serum $25(\mathrm{OH}) \mathrm{D}$ levels for visit 1 and visit $2(\mathrm{n}=40) \ldots \ldots \ldots \ldots . \ldots 44$

8. Individual Sun Exposure Index (SEI) (BSA x mins) and serum 25hydroxyvitamin $\mathrm{D}$ during visit.

9. Individual Sun Exposure Index (SEI) (BSA x mins) and serum 25hydroxyvitamin D during visit 2 .

10. Individual vitamin $D$ intake (including food and supplements) during visit 1 and visit $2(n=40)$ as assessed by a vitamin $D$ specific food frequency questionnaire.

11. Correlation between the individual Vitamin D Intake (IU/day) and serum 25 -hydroxyvitamin $\mathrm{D}$ during visit 1 ....

12. Correlation between the Forehead Skin Reflectance $\left(L^{*}\right)$ and serum 25 -hydroxyvitamin $\mathrm{D}$ during visit 1 


\section{Introduction}

Vitamin $D$ is recognized for its role in numerous metabolic functions, and is crucial for the growth, development and health of all individuals (Holick, 2004a). In the United States and worldwide, conditions directly related to low vitamin D status are a tremendous economic burden (Bueno \& Czepielewski, 2008). In the US alone, 1.5 to 2 million incident fractures occur annually, with the direct medical costs of osteoporosis estimated to be $\$ 13.7-20.3$ billion per year (Bueno \& Czepielewski, 2008). Worldwide it is estimated over 200 million people suffer from osteoporosis, a chronic bone disease (Cummings \& Melton, 2002). Vitamin D deficiency and related complications continue to increase, adding to the global burden of deficiency.

Vitamin $D$ is ingested from food and supplements or synthesized from exposure to sunlight. The sun remains a free and high-quality source of potential vitamin D, however sun exposure guidelines are nearly impossible to set. Not only are there controversial beliefs about sun exposure because of the risk of skin cancer, but environmental factors such as season, latitude, altitude and time of day greatly affect synthesis of vitamin D. Individual factors such as skin pigment, sunscreen use, clothing and age also affect the amount of vitamin $D$ synthesized. Thus, it is difficult to quantify the sun exposure individuals receive and determine how exposure contributes to vitamin D status.

The Dietary Reference Intakes (DRI) for vitamin D were originally set in 1997, but with much consideration they were updated in 2010. Setting the new 
guidelines was challenging because vitamin $D$ is not naturally found in many foods. However, new guidelines were needed because current literature has shown that vitamin D deficiency is a worldwide issue (IOM, 2010). At the same time, research has eluded to numerous other health effects of vitamin D that need to be considered for optimal health (IOM, 2010). However, even with the emerging roles of vitamin $\mathrm{D}$, bone health was the only marker with enough data to support a role for adequate status (IOM, 2010). Consequently, reference intakes for vitamin D tripled from $200 \mathrm{IU} /$ day to $600 \mathrm{IU} /$ day for individuals aged 1 to 70 years (IOM, 2010).

\section{Metabolism}

\section{Forms of Vitamin D}

Vitamin D has two forms, ergocalciferol, commonly referred to as vitamin $D_{2}$, derived primarily from plant-based foods and some dietary supplements (Holick, 2006a) and cholecalciferol, commonly referred to as vitamin $D_{3}$, derived primarily from sun exposure, animal based foods, and dietary supplements (Holick, 2006a). Previtamin $D_{3}$ is located in the skin and synthesized to vitamin $D$ upon exposure to sunlight (Bikle, 2007). The structures of vitamin $D_{2}$ and vitamin $D_{3}$ differ only in their side chains; vitamin $D_{2}$ contains a double bond between carbons 22 and 23 and a methyl group at carbon 24, while vitamin $D_{3}$ does not (Bikle, 2007). This structural difference causes vitamin $D_{2}$ to be less bioavailable than vitamin $\mathrm{D}_{3}$ (Bikle, 2007). 


\section{Production and Metabolism}

Previtamin $D_{3}$ and vitamin $D_{3}$ synthesized from exposure to sunlight does not lead to toxicity because it is broken down with further ultraviolet B (UVB) radiation to inert photoproducts (Holick, MacLaughlin \& Doppelt, 1981). As previtamin $D_{3}$ is produced in the skin, it can be converted to vitamin $D_{3}$ or into biologically inert photoisomers, lumisterol and tachysterol upon further UVB exposure. Thus, sunlight can act as a regulator of vitamin $\mathrm{D}_{3}$ production and prevent against intoxication (Holick, MacLaughlin \& Doppelt, 1981).

Although vitamin D synthesized from exposure to sunlight will not lead to toxicity, vitamin $D_{3}$ intoxication may occur when the daily dose of supplements are in excess of 10,000 IU/d for more than eight weeks (Holick, 2002). The immediate symptoms of vitamin D overdose include abdominal cramps, nausea and vomiting (ODS, 2010). While long term complications may include hypercalcuria (calcium in urine), hypercalcemia (high blood calcium), weakness, weight loss, tingling sensations in the mouth, confusion and heart rhythm abnormalities (ODS, 2010).

Vitamin $D$ is synthesized in the skin from exposure to the sun's UVB radiation which is the portion of the electromagnetic spectrum ranging from 290320 namometers (nm) (MacLaughlin, Anderson \& Holick, 1982). Previtamin. During exposure to sunlight, 7-dehydrocholesterol (7-DHC) located in the skin, is quickly converted to previtamin $\mathrm{D}_{3}$ (MacLaughlin, Anderson \& Holick, 1982). Previtamin $D_{3}$ undergoes a thermally induced transformation to form vitamin $D_{3}$ which then enters circulation (MacLaughlin, Anderson \& Holick, 1982). Vitamin 
$D_{3}$ undergoes its first hydroxylation in the liver by the 25 -hydroxylase (25OHase) enzyme to $25(\mathrm{OH}) \mathrm{D}_{3}$ (Holick, 2004a). Vitamin D's second and final hydroxylation occurs in the kidney by the 1a-hydroxylase enzyme to $1,25(\mathrm{OH})_{2} \mathrm{D}_{3}$ (Holick, 2004a) (Figure 1). Hydroxylation of $25(\mathrm{OH}) \mathrm{D}$ and $1,25(\mathrm{OH})_{2} \mathrm{D}$ also occurs at the 24 carbon by 24 -hydroxylase, yielding $24,25(\mathrm{OH})_{2} \mathrm{D}$ and 1,24 , $25(\mathrm{OH})_{3} \mathrm{D}$ (Prentice, Goldberg \& Schoenmakers, 2008). These metabolites are formed to prevent toxicity (Prentice, Goldberg \& Schoenmakers, 2008).

Serum $25(\mathrm{OH}) \mathrm{D}$ is the prominent circulating form of vitamin $\mathrm{D}$, with a half life of 2-3 weeks, in comparison to $1,25(\mathrm{OH})_{2} \mathrm{D}$ with a half life of $4-6$ hours (Prentice, Goldberg \& Schoenmakers, 2008). Serum 25(OH)D is also less regulated and therefore more accurately reflects the individual's vitamin D intake and overall production.

It is also important to note that vitamin D produced in the skin remains in circulation longer than vitamin $D$ ingested from the diet, despite the fact that they have the same biological activity once metabolized. This is due to the fact vitamin D produced in the skin is $100 \%$ bound to vitamin D binding protein (DBP), while vitamin D from food sources is only $60 \%$ bound (Haddad, Matsuoka, Hollis, Hu \& Wortsman, 1993).

$1,25(\mathrm{OH})_{2} \mathrm{D}_{3}$ is the active form of vitamin $\mathrm{D}$ and is more tightly regulated by the body than $25(\mathrm{OH})$ D. $1,25(\mathrm{OH})_{2} \mathrm{D}_{3}$ is mainly responsible for regulating calcium metabolism by increasing the breakdown of calcium from bones, retaining calcium in the kidney and increase calcium absorption in intestines (Prentice, Goldberg \& Schoenmakers, 2008). The vitamin D receptor, which 
responds to the active form of vitamin $D$ is located on numerous cells throughout the body including the brain, prostate, colon, lung and immune cells (Prentice, Goldberg \& Schoenmakers, 2008). It is also estimated that the active form of vitamin D controls over 200 genes and has multiple functions related to the suppression of multiple diseases (Prentice, Goldberg \& Schoenmakers, 2008).

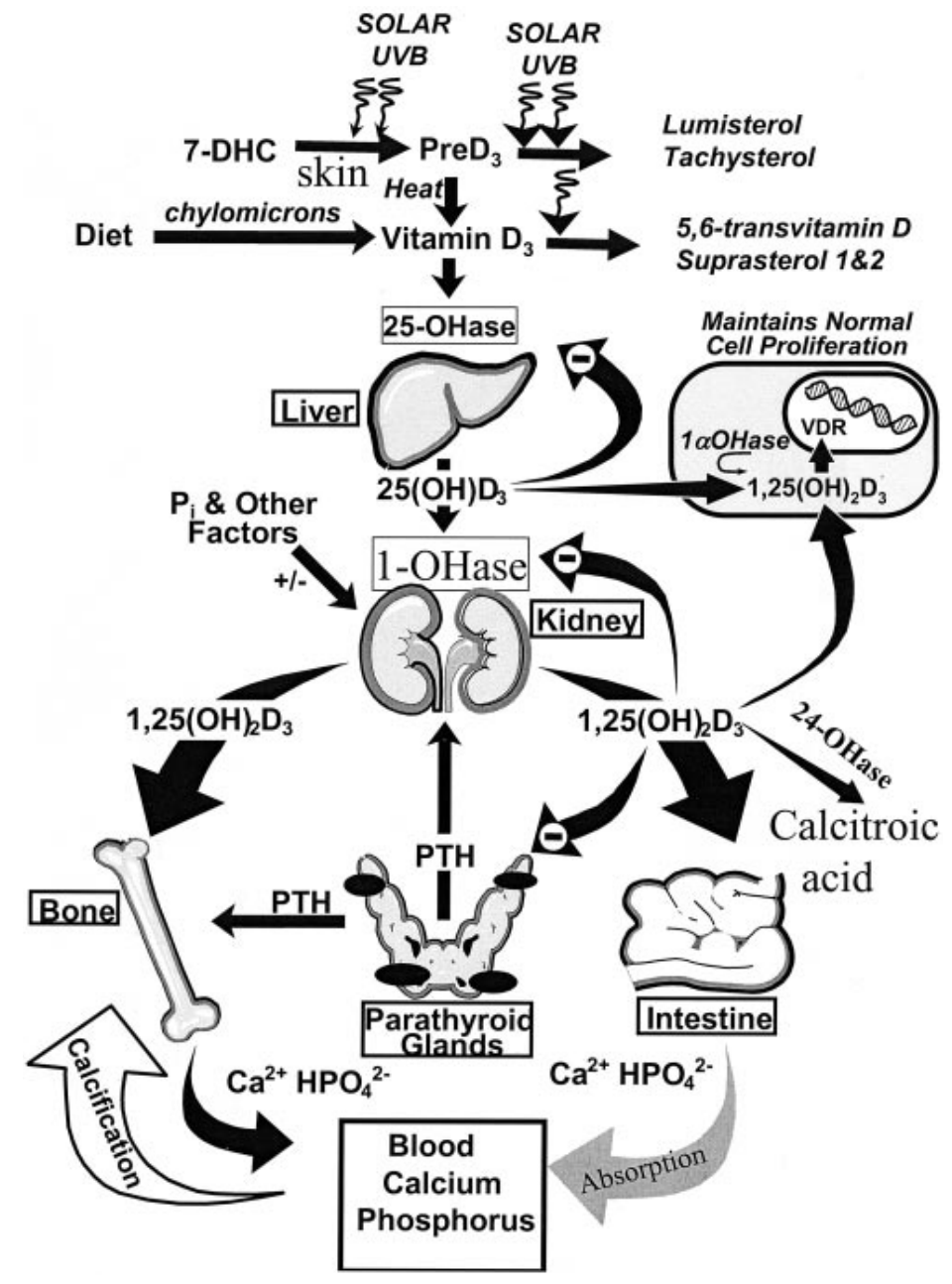

FIGURE 1: Vitamin D Production and Metabolism

Holick, 2004a. 


\section{Factors Affecting Vitamin D Absorption/Synthesis}

\section{Dietary Factors}

Certain foods, such as fiber and ethanol, reduce the bioavailability of vitamin D because these foods provoke biliary excretion (Bueno \& Czepielewski, 2008). Other foods such as milk and dairy, increase the absorption of vitamin D three to 10 times due to the presence of lactalabumin, a long chain fatty acid that facilitates vitamin D absorption (Bueno \& Czepielewski, 2008).

\section{Environmental Factors}

Vitamin D produced in the skin is a two-stage process that begins with the production of previtamin D after irradiation of 7-dehydrocholesterol (7-DHC) by UVB radiation (Webb, 2006). Environmental factors including latitude, altitude, time of day and time of year drastically alter the probability of UV photons reaching 7-DHC in the skin. For example, latitude is indicative of how close or far an individual lives from the equator, where solar radiation is the most intense (Webb, Pilbeam, Hanafin \& Holick, 1990) (Figure 2). The farther away that an individual resides from the equator, the less UVB radiation is available for vitamin D synthesis (Webb, Pilbeam, Hanafin \& Holick, 1990). As UV radiation travels down a path, the length of the path that the photons travel through the ozone layer is known as the solar zenith angle (SZA) (Webb, 2006). The SZA is defined as the difference in degrees of the position of the sun to the earth compared to when the sun is directly overhead (Webb, 2006). For instance, in the winter months the SZA is larger and with the sun lower in the sky there is more atmosphere for the UVB photons to travel through (Webb, 2006). At higher 
latitudes and during the wintertime, the UVB photons may not even reach the earth to contribute to vitamin D synthesis in the skin. Therefore, large SZAs are a feature of winter, early morning and late afternoon and higher latitudes while small SZAs are a feature of summer, noon and lower latitudes and ultimately changes the SZA with the season, latitude and time of day (Webb, 2006).

Altitude is another important factor because at higher altitudes, the UVB radiation is stronger and therefore, more vitamin $\mathrm{D}$ can be made (Webb, Pilbeam, Hanafin \& Holick, 1990). Time of day is important because UVB radiation is the most intense and direct at noon due to the smaller SZA), therefore allowing an individual to synthesize more vitamin D during that time. The length of time, or minutes, in the sun is another determinate that alters the amount of vitamin D synthesized in the skin because the more time an individual is in the sun, the more vitamin D he/she will synthesize in the skin (Webb, Pilbeam, Hanafin \& Holick, 1990). Time of year is also important to consider because an individual is more likely to synthesize vitamin $D$ in the summer months due to the sun being closer to the earth (i.e. smaller SZA) and more skin is exposed with typical summer clothing (Webb, Pilbeam, Hanafin \& Holick, 1990). There are also transient factors such as clouds and air pollution that affect the amount of UVB radiation reaching the earth and ultimately influencing the amount of vitamin D that can be made in the skin (Webb, Pilbeam, Hanafin \& Holick, 1990). 


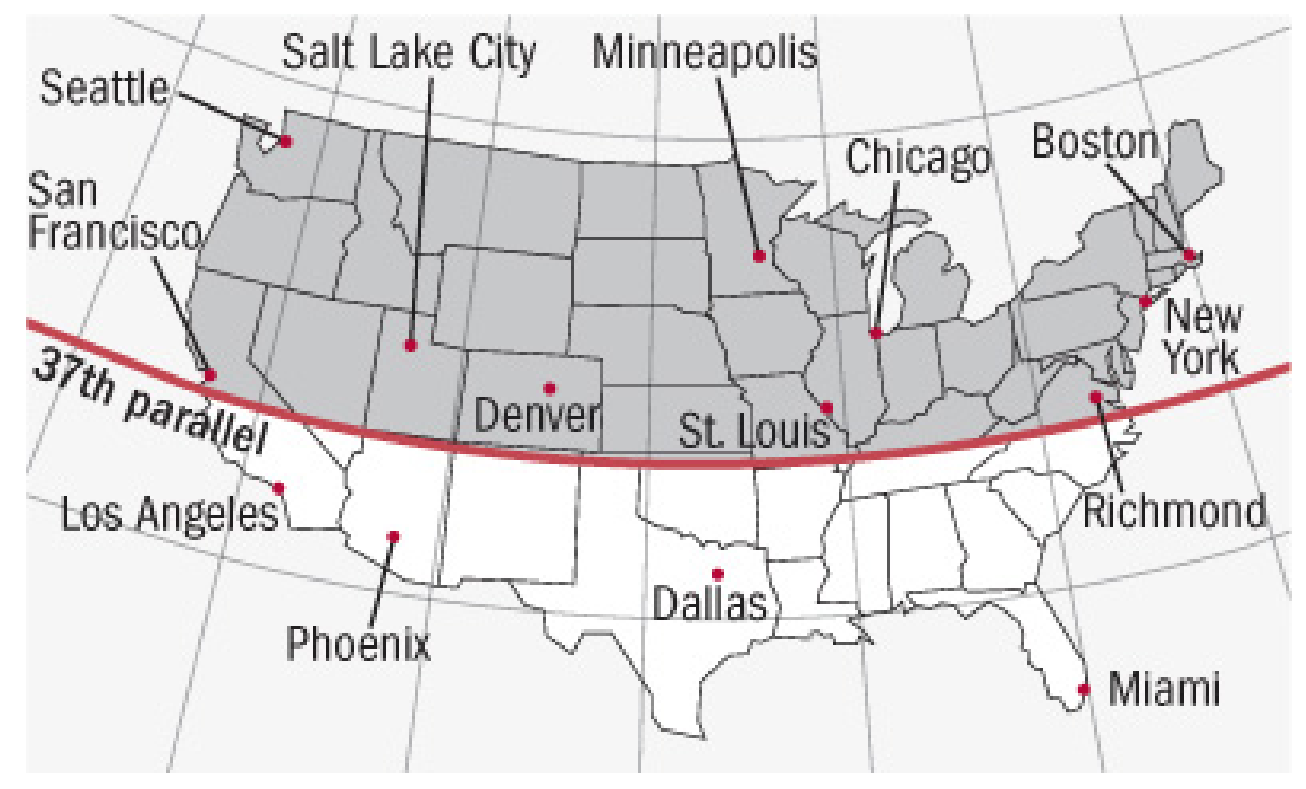

Figure 2: $37^{\text {th }}$ Parallel Latitude of the United States

Except during the summer months, the skin makes little vitamin $D$ from the sun at latitudes above 37 degrees north (above red line; the shaded region in the map) or below 37 degrees south of the equator. People who live in these areas are at relatively greater risk for vitamin $D$ deficiency.

Webb, Pilbeam, Hanafin \& Holick, 1990.

\section{Individual-level Factors}

Numerous individual-level factors alter synthesis of vitamin D in the skin, including the amount of clothing worn (ie. body surface area (BSA) exposed), sunscreen use, age, obesity and skin pigmentation.

Clothing worn and sunscreen use are two modifiable barriers to sun exposure that inhibit synthesis of vitamin $D$ in the skin by blocking UVB radiation. Age is another an individual-level factor that alters the amount of vitamin D synthesized, however this is non-modifiable. For example, healthy young adults and elderly adults were exposed to the same amount of a whole-body dose of UV radiation (MacLaughlin, Anderson \& Holick, 1982). Within a 24 hour period 
serum $25(\mathrm{OH}) \mathrm{D}$ in the young adults increased to a maximum of $78.1 \mathrm{nmol} / \mathrm{L}$ while the older adults (62-80 years old) reached a maximum level of $20.8 \mathrm{nmol} / \mathrm{L}$ (MacLaughlin, Anderson \& Holick, 1982). The skin samples from the older adults contained half the amount of previtamin $D_{3}$ compared to the younger skin samples compromising their ability to synthesize vitamin $D$ in their skin (MacLaughlin, Anderson \& Holick, 1982). Older adults are also less likely to get adequate sun exposure based on lifestyle choices, such as remaining indoors (MacLaughlin, Anderson \& Holick, 1982). Therefore, age is a risk factor for vitamin D deficiency.

Overweight and obesity is also an individual-level factor that alters the body's ability to metabolize and utilize vitamin D effectively (Wortsman, Matsuoka, Chen, Lu \& Holick, 2000). This is a concern because recent data from the Centers for Disease Control (CDC) indicate that one-third of U.S adults (33.8\%) were obese, and almost two-thirds of U.S. adults (64.1\%) were overweight/obese in 2010 (CDC, 2010).

Wortsman et al. (2000) found that obese individuals were $50 \%$ less likely to increase their serum 25(OH)D when compared to normal weight individuals after exposure to UVB radiation (Wortsman, Matsuoka, Chen, Lu \& Holick, 2000). They also found that a high BMI was inversely correlated with peak serum concentrations of $25(\mathrm{OH}) \mathrm{D}$ after oral administration of vitamin $\mathrm{D}$. It was speculated that there is decreased bioavailability of vitamin $D$ because it is deposited in body fat suggesting that the increased amount of subcutaneous fat in overweight/obese individuals alters the release of vitamin $D$ and inhibits the 
body's ability to utilize this nutrient (Wortsman, Matsuoka, Chen, Lu \& Holick, 2000). In addition, as the level of obesity and body fat increased, plasma concentrations of $25(\mathrm{OH}) \mathrm{D}$ decreased, especially in individuals with a $\mathrm{BMI} \geq 30$ $\mathrm{kg} / \mathrm{m}^{2}$. In order to correct a vitamin D deficiency in obese individuals, it is thought that higher doses of vitamin D are needed to correct the body's inefficient utilization (Wortsman, Matsuoka, Chen, Lu \& Holick, 2000) although research has not determined the most appropriate dose.

Skin pigmentation is an important individual-level factor that alters the amount of vitamin D synthesized. Skin pigmentation reflects of the amount of melanin in an individual's skin. Melanin is responsible for giving skin color and providing protection from the sun by absorbing UVB radiation (Matsuoka, Wortsman, Haddad, Kolm \& Hollis, 1991). The darker an individual's skin pigmentation, the more melanin they have, and consequently the less vitamin $D$ that can be synthesized. Thus, longer periods of sun exposure are required for equivalent vitamin D synthesis in people with darker skin or African American ancestry, compared with those of lighter skin or European ancestry (Matsuoka, Wortsman, Haddad, Kolm \& Hollis, 1991).

Armas et al. (2007) conducted a study to determine the relationship between UVB exposure and 25(OH)D levels as a function of skin pigmentation (i.e. reflectance) (Armas et al., 2007). They measured skin reflectance using the $L^{*}$ (lightness) value and included study participants with various skin pigmentations. The participants were exposed to UVB radiation on $90 \%$ of their body surface area (BSA) 3 times a week for 4 weeks and had their serum 
$25(\mathrm{OH}) \mathrm{D}$ levels measured weekly (Armas et al., 2007). They found that $80 \%$ of the variation in $25(\mathrm{OH}) \mathrm{D}$ was explained by the UVB dose and skin pigmentation (Armas et al., 2007). They also found an association between unexposed skin color and baseline serum 25(OH)D with lighter skin color being associated with higher 25(OH)D levels (Armas et al., 2007). Armas et al. (2007) also showed that skin pigment alone doesn't explain 25(OH)D levels because behavior in the sun is an important factor to consider. They conducted a study in France and classified skin phototype according to hair color, complexion, susceptibility to burning, and tanning ability (Armas et al., 2007). They found the fairer skinned phototypes had lower levels of $25(\mathrm{OH}) \mathrm{D}$, contrary to their previous finding but attributed this to the fact that fairer skinned participants were likely to avoid the sun because of their tendency to burn (Armas, et al., 2007). They also found darker phototypes reported more sun exposure in this group of individuals (Armas et al., 2007). Both skin pigmentation and behavior in the sun are important to consider because they influence vitamin $D$ status.

\section{Functions of Vitamin D}

\section{Calcemic Functions}

Vitamin $D$ is needed for efficient absorption of dietary calcium and ultimately the formation of bone (Heaney, 2007). This is accomplished by calcium absorption from intestine, calcium retention by the kidney and calcium mobilization from the bone (Suda, Ueno, Fujii \& Shinki, 2002). A study by Bueno \& Czepielewski (2008) found that $30 \%$ of dietary calcium was absorbed when consumed with vitamin $\mathrm{D}$, while more than $60-80 \%$ of dietary calcium is absorbed 
when consumed with vitamin D during periods of growth. They also found that if milk is consumed at the same time as natural vitamin D food sources are eaten, absorption of calcium will increase 3-10 times (Bueno \& Czepielewski, 2008). Together, calcium and vitamin D are essential elements for skeletal health, fighting against age-related bone loss and fragility fractures (Heaney, 2007). In addition to bone formation, $1,25(\mathrm{OH})_{2} \mathrm{D}_{3}$ stimulates osteoblasts to produce receptor activator nuclear factor-к $\beta$ ligand (RANKL) which activates osteoclasts for bone reabsorption, ultimately promoting bone formation (Suda, Ueno, Fujii \& Shinki, 2002).

\section{Non-Calcemic Functions of Vitamin D}

Vitamin D has many non-calcemic functions, or roles outside of regulating blood calcium levels (Holick, 2004a). Vitamin D deficiency and insufficiency have been linked to certain chronic diseases including cardiovascular disease, diabetes, hypertension, cancer (Holick, 2004b), autoimmune diseases, susceptibility to infection, (Heaney, 2008) and obesity (Holick, 2006b). Vitamin D receptors are present in many organs, tissues and cells in the body including the brain, colon, breast, prostate, pancreas, heart, skin, skeletal muscle, monocytes, and activated T and B lymphocytes (DeLuca, 2004).

\section{Cancer}

$1,25(\mathrm{OH})_{2} \mathrm{D}$ may express autocrine properties important for regulating cell growth while decreasing the development of malignant cells (Holick, 2006a). It is now recognized that $1,25(\mathrm{OH})_{2} \mathrm{D}$ helps control the expression of more than 200 genes and it is thought that $1,25(\mathrm{OH})_{2} \mathrm{D}$ maintains cellular health by preventing 
the growth of malignant cells (Holick, 2006a). In fact, a reduction in malignant tissue growth was observed in colon, prostate, and breast cells when exposed to 1,25(OH) $)_{2} \mathrm{D}$ (Holick, 2006a).

A relationship between higher latitude (lower sunshine exposure) and higher cancer prevalence and mortality has been reported in ecological studies (Boscoe \& Schymura, 2006). Boscoe \& Schymura (2006) examined UVB exposure and cancer incidence and mortality in the US from 1993-2002 and after adjusting for cofounding variables in non-Hispanic whites found an inverse relationship for ten sites: bladder, colon, Hodgkin lymphoma, myeloma, other biliary, prostate, rectum, stomach, uterus and vulva. Weaker evidence of an inverse relationship was found for breast, kidney, leukemia, non-Hodgkin lymphoma, pancreas and small intestine (Boscoe \& Schymura, 2006).

A study conducted by Garland et al. (2007) found that 1,500 IU/day of supplemented vitamin $D_{3}$ corresponded with a $29 \%$ reduction in male cancer mortality and a 50\% reduction in colorectal cancer incidence. Additional cancer research by Giovannucci et al. (2006) found a $50 \%$ reduction in breast cancer with vitamin D dosages of $4,000 \mathrm{IU}$ per day. These studies demonstrate that doses of vitamin $D$ higher than the current recommended dietary allowance (RDA) may be associated with a reduction in cancer.

\section{Cardiovascular Health}

A study by Zitterman (2003) found that low vitamin D levels were correlated with the pathogenesis of heart failure and also associated with regulations of anti-inflammatory cytokines (Zitterman, 2003). Recent studies by 
Dobnig et al. (2008) showed that low $25(\mathrm{OH}) \mathrm{D}$ and $1,25(\mathrm{OH})_{2} \mathrm{D}$ levels were independently associated with all-cause mortality and cardiovascular morbidity in women and men (Dobnig et al., 2008). Wang et al. (2008) found that inadequate $25(\mathrm{OH}) \mathrm{D}$ status $(<45.7 \mathrm{nmol} / \mathrm{L})$ was associated with an increased risk of cardiovascular events, while adequate serum 25(OH)D (> $45.7 \mathrm{nmol} / \mathrm{L})$ was associated with a $44 \%$ reduction in fatal and non-fatal cardiovascular events (Wang et al., 2008). These studies demonstrate that there is an association between vitamin $\mathrm{D}$ and cardiovascular health.

\section{Diabetes}

Research suggests that vitamin D may suppress type 1 diabetes mellitus and prevent the destruction of islet cells (Zella \& DeLuca, 2003). A study in Finland found an $80 \%$ reduction in the risk of developing type 1 diabetes when 2,000 IU of vitamin D was consumed per day during the child's first year of life (Zella \& DeLuca, 2003). This cohort study lasted 31 years, starting with children deficient in vitamin $\mathrm{D}$ by the age of one. A deficiency at such a young age increased their risk of developing type 1 diabetes by 2.4 fold, but was found to be reversible with appropriate supplementation (Zella \& DeLuca, 2003). Holick (2004a) also studied vitamin D's effect on type 1 diabetes in a variety of animal models. He concluded that treatment with $1,25(\mathrm{OH})_{2} \mathrm{D}$ is effective in mitigating or preventing the onset of type 1 diabetes mellitus (Holick, 2004a).

Holick (2004a) continued his research and found a correlation between vitamin $\mathrm{D}$ and type 2 diabetes. He determined that pancreatic islet $\beta$ cells have a vitamin D receptor (VDR) which stimulates insulin secretion and hypothesized 
that hypovitaminosis $D$ in children may increase their risk of type 2 diabetes in adulthood, leading to insulin resistance and islet $\beta$ cell dysfunction (Holick, 2004a). Holick's research concluded that vitamin D deficiency along with decreased exposure to solar UVB radiation increased the risk of type 1 diabetes and may be associated with type 2 diabetes (Holick 2004a).

\section{Sources of Vitamin D}

\section{Dietary}

Very few foods naturally contain vitamin $D$, however the best sources include oily fish (i.e. salmon, mackerel, herring), cod liver oil and mushrooms (Bueno \& Czepielewski, 2008) (Table 1). In the US certain fortified foods such as milk, margarine, cereals and orange juice are also considered good sources of vitamin D (Bueno \& Czepielewski, 2008). However, the amount of vitamin D in fortified products varies depending on the manufacturer (Bueno \& Czepielewski, 2008).

\section{Sun Exposure}

A full day of sun exposure in a swimsuit may produce 10,000-20,000 IU's of vitamin $D$, whereas milk fortified with vitamin D, typically contains $100 \mathrm{IU}$ of vitamin D per 8 fluid ounces (Bueno \& Czepielewski, 2008). Therefore, when sunlight is available, sun exposure remains the most potent, reliable and economical source of vitamin D (Bueno \& Czepielewski, 2008). 
Table 1: Food Sources of Vitamin D

\begin{tabular}{|l|c|}
\hline Food & $\begin{array}{c}\text { IUs per } \\
\text { serving }\end{array}$ \\
\hline Cod liver oil, 1 tablespoon & 1,360 \\
\hline Salmon (sockeye), cooked, 3 ounces & 794 \\
\hline Mushrooms & 400 \\
\hline Mackerel, cooked, 3 ounces & 388 \\
\hline \hline Tuna fish, canned in water, drained, 3 ounces & 154 \\
\hline \hline Milk, nonfat, reduced fat, and whole, vitamin D-fortified, 1 cup & $115-124$ \\
\hline \hline Orange juice fortified with vitamin D, 1 cup & 100 \\
\hline \hline Yogurt, fortified with 20\% of the DV for vitamin D, 6 ounces & 80 \\
\hline \hline Margarine, fortified, 1 tablespoon & 60 \\
\hline \hline Sardines, canned in oil, drained, 2 sardines & 46 \\
\hline \hline Liver, beef, cooked, 3.5 ounces & 46 \\
\hline \hline Ready-to-eat cereal, fortified with 10\% of the DV for vitamin D, 1 cup & 40 \\
\hline \hline Egg, 1 whole (vitamin D is found in yolk) & 25 \\
\hline Cheese, Swiss, 1 ounce & 6 \\
\hline \hline
\end{tabular}

* An international unit (IU) is an internationally accepted amount of a substance and often used when standardizing measurements (40 IU = 1ug).

ODS, 2009. 


\section{Vitamin D Deficiency}

\section{Prevalence of Deficiency in the United States}

Several studies have shown high levels of vitamin D insufficiency across the United States. The National Health \& Nutrition Examination Survey (NHANES) is an ongoing study conducted by the National Center for Health Statistics to assess the health and nutritional status in the non-institutionalized US population and track changes over time (CDC, 2011). The 2001-2006 NHANES data found that two-thirds (67\%) of the US population over 1 year of age had sufficient $25(\mathrm{OH}) \mathrm{D}$ values ranging from $50-125 \mathrm{nmol} / \mathrm{L}$ (Looker et al., 2011) (Table 2). Nearly a quarter of the population were at risk of inadequate serum 25(OH)D levels ranging from $30-49 \mathrm{nmol} / \mathrm{L}$, while eight percent of the population was at risk of deficiency defined as $<30 \mathrm{nmol} / \mathrm{L}$ (Looker et al., 2011) (Table 2). Toxic vitamin D levels were found in $1 \%$ of the population and was defined as > $125 \mathrm{nmol} / \mathrm{L}$ (Looker et al., 2011). 
Table 2: National Center for Health Statistics percentile data for serum $25(\mathrm{OH}) \mathrm{D}$

\section{NCHS Data Brief a No. 59 a March 2011}

\begin{tabular}{|c|c|c|c|c|c|c|c|c|}
\hline \multirow[b]{2}{*}{ Characteristic } & \multirow[b]{2}{*}{$n$} & \multicolumn{7}{|c|}{ Serum $250 H D$ (nmol/L) percentile } \\
\hline & & 5th & 10th & 25 th & 50 th & 75th & 90th & 95th \\
\hline \multicolumn{9}{|c|}{ Male } \\
\hline \multicolumn{9}{|l|}{ Age (years) } \\
\hline $1-3$ & 581 & 40.7 & 48.3 & 58.2 & 69.5 & 84.4 & 94.7 & 101.0 \\
\hline $4-8$ & 970 & 42.6 & 47.8 & 58.0 & 67.3 & 78.8 & 92.0 & 89.8 \\
\hline$\theta-13$ & 1.473 & 32.5 & 40.4 & 49.8 & 621 & 74.5 & 87.4 & 88.5 \\
\hline $14-18$ & 1,978 & 25.3 & 33.0 & 45.7 & 58.5 & 71.2 & 84.9 & 85.7 \\
\hline $19-30$ & 1,611 & 23.0 & 29.4 & 41.8 & 55.3 & 68.7 & 83.6 & 94.3 \\
\hline $31-50$ & 2,244 & 25.1 & 31.3 & 44.2 & 57.4 & 71.5 & 84.5 & 94.3 \\
\hline $51-70$ & 1,853 & 25.6 & 32.7 & 44.1 & 58.1 & 71.3 & 83.7 & 91.8 \\
\hline Over 70 & 1,217 & 25.4 & 31.7 & 44.6 & 57.2 & 69.7 & 82.7 & 80.1 \\
\hline \multicolumn{9}{|c|}{ Female } \\
\hline \multicolumn{9}{|l|}{ Age (years) } \\
\hline $1-3$ & 584 & 43.3 & 49.8 & 58.5 & 68.3 & 79.4 & 89.2 & 84.8 \\
\hline $4-8$ & 989 & 38.4 & 44.2 & 54.5 & 67.2 & 80.0 & 93.4 & 101.0 \\
\hline $9-13$ & 1,515 & 27.7 & 34.6 & 46.3 & 57.6 & 68.4 & 80.9 & 87.5 \\
\hline $14-18$ & 1,823 & 20.8 & 27.2 & 41.1 & 57.2 & 71.6 & 87.1 & 104.0 \\
\hline $19-30$ & 1,346 & 18.5 & 25.4 & 40.0 & 55.8 & 76.2 & 95.6 & 111.0 \\
\hline $31-50$ & 2,097 & 18.2 & 25.3 & 38.8 & 55.3 & 71.0 & 87.6 & 101.0 \\
\hline $51-70$ & 1,868 & 21.2 & 27.0 & 39.7 & 54.7 & 69.7 & 85.4 & 83.4 \\
\hline Over 70 & 1,197 & 22.6 & 27.1 & 40.5 & 55.5 & 69.6 & 84.1 & 83.6 \\
\hline $\begin{array}{l}\text { Pregnant or } \\
\text { lactating }\end{array}$ & 1,087 & 24.5 & 31.4 & 44.5 & 62.4 & 78.2 & 94.7 & 109.0 \\
\hline
\end{tabular}

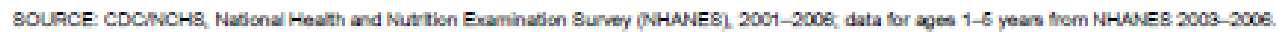

Looker et al., 2011.

Racial/ethnic differences in vitamin D status were observed after adjusting for age and season. Non-Hispanic white persons were less likely to be at risk of deficiency $(<30 \mathrm{nmol} / \mathrm{L})$ or at risk of inadequacy $(30-49 \mathrm{nmol} / \mathrm{L})$ than nonHispanic black or Mexican American persons (Looker et al., 2011). However, the Institute of Medicine (IOM) has debated the interpretation of correlating race with serum $25(\mathrm{OH}) \mathrm{D}$ levels. This is because they found that many nonwhite groups 
have higher bone density scores than white groups, despite having lower serum 25(OH)D values (Looker et al., 2011). Due to this discrepancy, the IOM concluded that serum $25(\mathrm{OH}) \mathrm{D}$ thresholds for risk of deficiency or inadequacy in nonwhite persons is uncertain based on bone health outcomes (Looker et al., 2011).

Vitamin D deficiency has steadily increased in the United States over the past few decades. NHANES data from 1988-1994 reported 3\% of males 12 years and older were at risk of deficiency $(<30 \mathrm{nmol} / \mathrm{L})$, while the 2001-2002 data found a $7 \%$ increase in vitamin $\mathrm{D}$ deficiency within the same population (Looker et al., 2011) (Figure 3). For females, the 1988-1994 data showed that $7 \%$ of those aged 12 and older were at risk of deficiency $(<30 \mathrm{nmol} / \mathrm{L})$, while 11\% were at risk in 2001-2002 (Looker et al., 2011). Despite the apparent increase in deficiency, the NHANES data indicate most people in the United States are sufficient in vitamin D, based on serum 25(OH)D thresholds proposed by IOM (Looker et al., 2011). In general the data found roughly one-quarter were at risk of inadequacy $(<50 \mathrm{mnol} / \mathrm{L})$ and $8 \%$ were at risk of deficiency $(<30$ nmol/L) (Looker et al., 2011). 


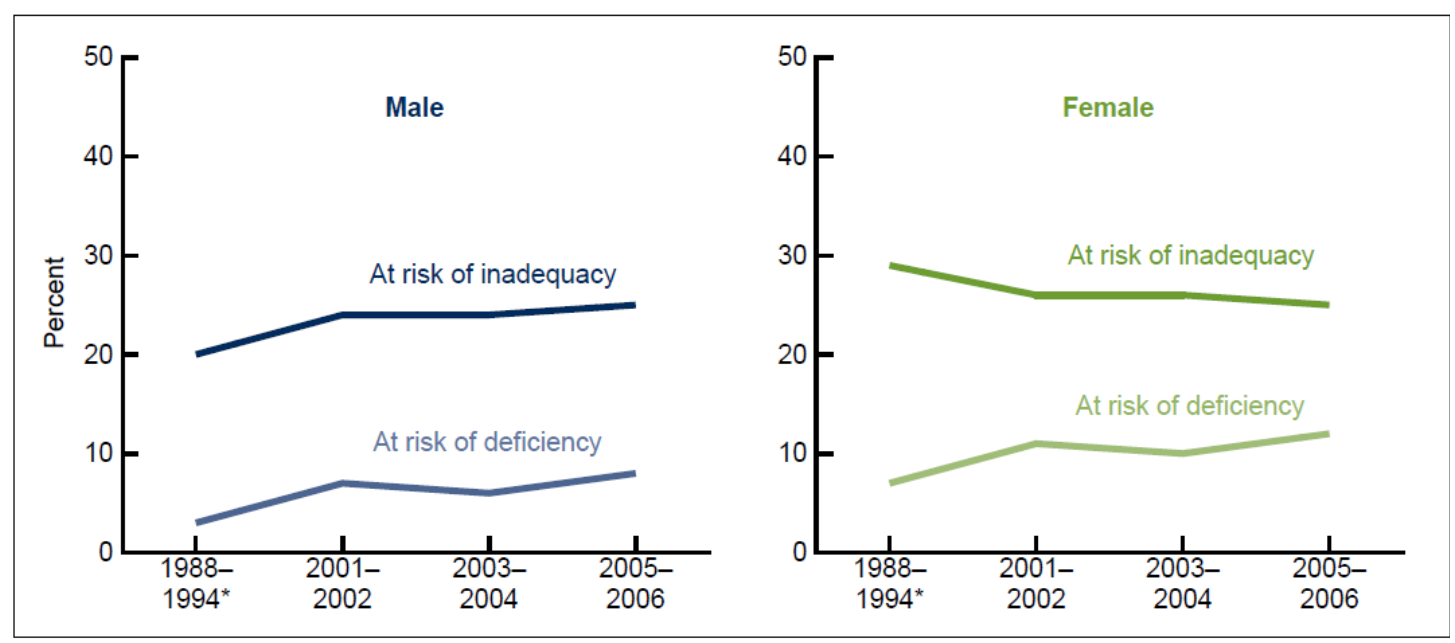

* Adjusted for assay difference between NHANES III and NHANES 2001-2006.

$\dagger p<0.05$ compared with preceding time period within sex.

NOTE: Significant overall trend in risk of deficiency and risk of inadequacy by survey period within sex, $p<0.05$

SOURCE: CDC/NCHS, National Health and Nutrition Examination Survey (NHANES).

Figure 3: Age and Serum-adjusted prevalence at risk of deficiency and Inadequacy among persons aged 12 years and over. United States, 19881994 through 2005-2006.

Looker et al., 2011.

\section{Vitamin D Intakes}

The National Health and Nutrition Examination Survey (NHANES 19992000) found that in the United States dietary intakes of vitamin D from food and supplements were categorized by age, sex, and race/ethnicity (i.e. non-Hispanic (NH) white, NH black, and Mexican American) (Moore, Murphy \& Holick, 2012). Vitamin D intakes were highest among children and teenagers, and lowest in the oldest age groups (Moore, Murphy \& Holick, 2012). Among children age 1-8 years old, adequate intake $(\mathrm{Al})$ levels for vitamin $\mathrm{D}$ from food were met or exceeded by $69 \%$ of Mexican Americans, $59 \%$ of $\mathrm{NH}$ whites, and $48 \%$ of $\mathrm{NH}$ blacks (Moore, Murphy \& Holick, 2012). For adults $\geq 51$ years old only $4 \%$ met or exceeded the Al from food alone. Few women 19-50 years old or men and 
women $\geq 51$ years old were estimated to consume recommended vitamin $D$ levels from food (Moore, Murphy \& Holick, 2012). Mean dietary intakes of vitamin D from food plus supplements were consistently highest among $\mathrm{NH}$ white adults (Moore, Murphy \& Holick, 2012). This NHANES survey found the largest discrepancy between vitamin $D$ intake by older individuals from food plus supplements and recommended levels for $\mathrm{NH}$ black and Mexican American adults compared to NH white adults (Moore, Murphy \& Holick, 2012).

\section{Consequences of Deficiency}

\section{Rickets}

Rickets in children was the first recognized disease of Vitamin D deficiency (Bueno \& Czepielewski, 2008). Rickets was prevalent in the $19^{\text {th }}$ century before the fortification of foods, access to dietary supplements and from a lack of knowledge regarding the synthesis of vitamin $D$ from exposure to sunlight. This condition has nearly disappeared in the United States due to the fortification of milk/foods and with adequate sun exposure (Bueno \& Czepielewski, 2008).

Other countries in Asia, The Middle East, and Africa have a much higher incidence of rickets than European countries. A study conducted by Prentence et al. (2006) found that $70 \%$ of the population in Mongolia, $66 \%$ in Tibet and $42 \%$ in Ethiopia are estimated to suffer from rickets; while only $1.6 \%$ of the population is estimated to have rickets in the United Kingdom (Prentence et al., 2006).

In the United States, African American children are most at risk for rickets because their darker skin pigmentation reduces their ability to produce 
cholecalciferol in their skin, as well as the interference of other lifestyle and dietary factors (Moore, Murphy \& Holick, 2012). NHANES data taken from 19992000 found that the lowest vitamin D intakes were amongst non-hispanic blacks. This is thought to be associated with an avoidance of fortified milk due to lactose maldigestion (Moore, Murphy \& Holick, 2012). African Americans were also found to use dietary supplements less frequently than whites.

Sir Edward Mellanby of Great Britain was the first to notice that rickets was due to a dietary deficiency. He found that dogs developed rickets when fed a diet primarily of oatmeal and were kept indoors and attributed this disease to a vitamin A deficiency (Rajakumar, 2003). McCollum was the first to discover vitamin $A$ in butter fat. He decided to extract the vitamin $A$ in the cod liver oil and retest the oil's ability to cure the rickets. McCollum found that by feeding the dogs the vitamin A-deficient cod liver oil, he still cured their rickets, and termed this unknown vitamin as "vitamin D". From the work of Mellanby and McCollum, vitamin D became known as an "essential nutrient" (Rajakumar, 2003).

Most cases of rickets occur between the ages of 4 and 12 months with bone deformities in both the upper and lower limbs prior to walking due to the muscle pull that occurs during growth (Holick, 2006a). Children with rickets tend to suffer from reduced growth and severe bone abnormalities, as well as an increased risk of developing bone fractures in adulthood (Bueno \& Czepielewski, 2008). Although rickets alters the entire bone mineralization process, the most hazardous areas are in the long bone epiphyses and the costochondral junctions 
of the body (Holick, 2006a). These are two of the main sites for bone growth, and clinical bone manifestations occur here as deficiency continues (Holick, 2006a).

The most effective treatment for rickets is to administer $20,000-60,000 \mathrm{IU}$ of vitamin $D_{2}$ or vitamin $D_{3}$ along with adequate calcium for least six months (Shah \& Finberg, 1994). Over the course of 6-10 days the body is able to drastically increase the amount of serum calcium and phosphorus in the blood, with the hopes of reversing the rickets over a period of 3-6 months (Garabedian \& Ben-Mekhbi, 1999). With proper treatment, rickets is a reversible condition. However, a primary prevention approach would include adequate vitamin D and calcium in infancy.

\section{Osteoporosis}

Osteoporosis is a serious and ongoing public health concern that impacts a large population. It is estimated that over 200 million people worldwide suffer from osteoporosis, while $30 \%$ of postmenopausal women are estimated to have osteoporosis in the United States and Europe (Cummings \& Melton, 2002). Based on the current bone health figures, by 2050 the worldwide incidence of hip fracture is projected to increase by $240 \%$ in women and $310 \%$ in men (Cummings \& Melton, 2002) (Figure 4). The number of hip fractures worldwide is estimated to increase from 1.66 million in 1990 to 6.26 million in 2050 , even if age-adjusted incidence rates remain stable (Cummings \& Melton, 2002) (Figure 4). 


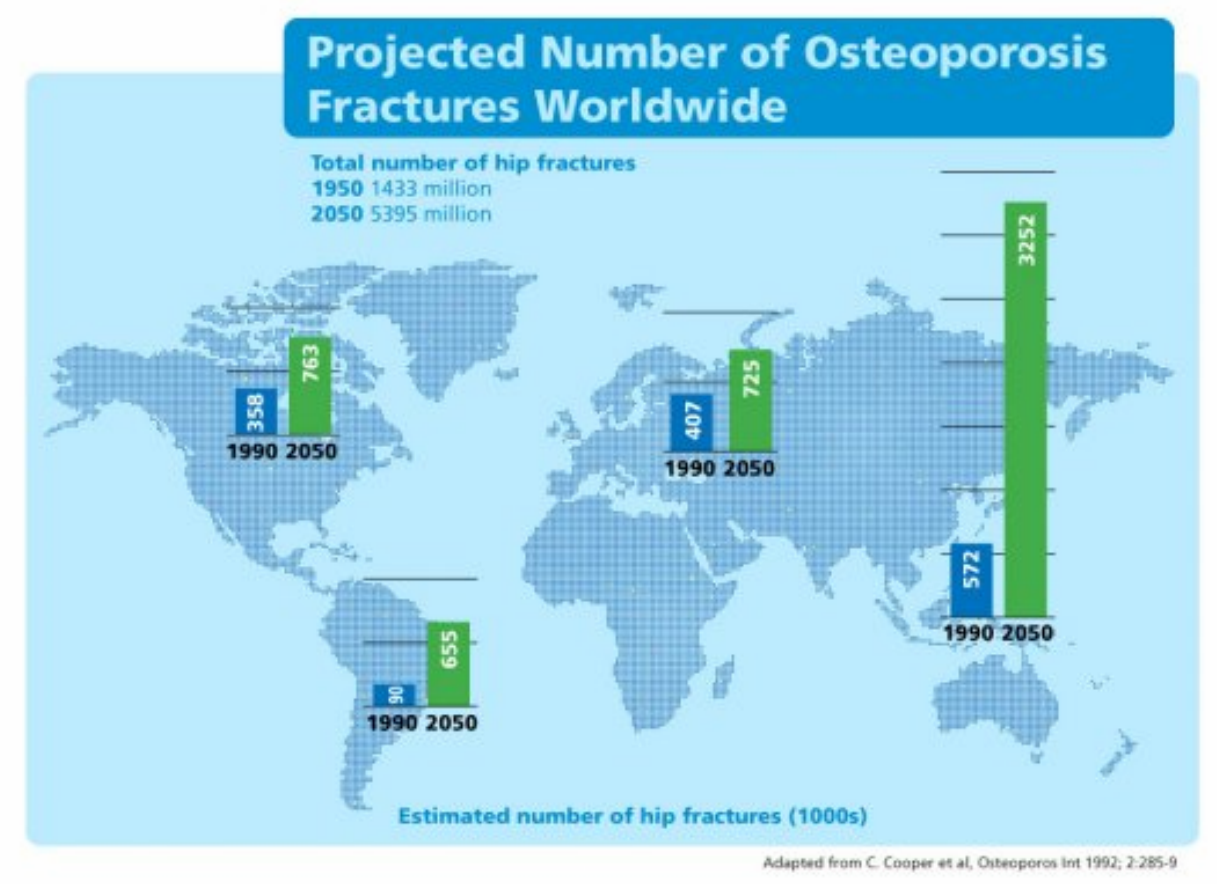

Figure 4: Incidence of Osteoporosis Fractures Worldwide.

Cummings \& Melton, 2002.

Osteoporosis literally means "porous bone", and is a bone density disease where the loss of bone occurs "silently" and progressively often with no symptoms (International Osteoporosis Foundation (IOF), 2010). The World Health Organization (WHO) defined osteoporosis using reference bone density measurements from a population of healthy young adults. Osteoporosis is diagnosed when a person's bone mineral density (BMD) is $\geq 2.5$ standard deviations below this reference measurement (IOF, 2010) (Table 3). Osteopenia, meaning "soft bone", is diagnosed when the measurement is between 1 and 2.5 standard deviations below the young adult reference measurement (IOF, 2010) (Table 3). 
Table 3: $T$-scores indicating bone mineral density diagnosis

\begin{tabular}{||l|l||}
\hline Status & Hip BMD \\
\hline Normal & T-score of -1 or above \\
\hline Osteopenia & T-score lower than -1 and greater than -2.5 \\
\hline Osteoporosis & T-score of -2.5 or lower \\
\hline $\begin{array}{l}\text { Severe } \\
\text { osteoporosis }\end{array}$ & $\begin{array}{l}\text { T-score of }-2.5 \text { or lower, and presence of at } \\
\text { least one fragility fracture }\end{array}$ \\
\hline
\end{tabular}

International Osteoporosis Foundation, 2010.

\section{Vitamin D Intake Recommendations}

\section{Background}

The Dietary Reference Intakes (DRI) are a set of guidelines for the daily intake of nutrients set by the Institute of Medicine (IOM) of the U.S. National Academy of Sciences (ODS, 2009). The Recommended Dietary Allowance (RDA) is the daily dietary intake level of a nutrient considered sufficient by the Food and Nutrition Board (FNB) to meet the requirements of nearly all (97-98\%) healthy individuals in each life-stage and gender group (ODS, 2009).

The DRI system is used by both the United States and Canada and is intended for the general public and health professionals. In 1997, the FNB of the IOM established a Dietary Reference Intake for vitamin D which included an adequate intake (AI) level and a tolerable upper level (UL) (ODS, 2009). The AI is a dietary guideline established to estimate nutrient needs when sufficient data 
is not available to establish an RDA. The Al for vitamin $\mathrm{D}$ was based on values known to effect bone health and calcium absorption, and assumed no sun exposure. The UL is defined as the highest level of daily consumption current data shows with no side effects in humans. The UL for vitamin D was established to prevent vitamin D-induced hypercalcemia, excess bone loss, and hyperphosphatemia (ODS, 2009).

In 2008, the American Academy of Pediatrics updated their policy guidelines to increase vitamin D recommendations for infants and children from 200 IU per day to 400 IU per day (Wagner \& Greer, 2008). In 2009, the IOM delegated a committee to review and revise the DRIs for vitamin D and calcium for the adult population (Institute of Medicine, Food \& Nutrition Board, 2009).

\section{Setting the New RDA}

DRI values for calcium and vitamin D were updated in 2010 from the previous guidelines set in 1997. The IOM established an ad hoc consensus committee of 14 scientists, all with expertise in the areas of vitamin D and calcium or a related topic area (Ross, Taylor, Yaktine \& Del Valle, 2010). The committee found bone health was the only potential indicator for vitamin $D$ adequacy that provided enough evidence when establishing the new vitamin $D$ guidelines (Ross, Taylor, Yaktine \& Del Valle, 2010). Outcomes related to cancer, cardiovascular disease, diabetes, physical performance, immune function, autoimmune disorders and others diseases provided conflicting and insufficient evidence, could not be reliably linked to vitamin D, and thus were not 
indicators used to develop the new RDA guidelines (Ross, Taylor, Yaktine \& Del Valle, 2010).

During this review, two major challenges were presented for Vitamin D. The first was that vitamin D is synthesized from exposure to sunlight. Not only is sun exposure difficult to access, but vitamin $D$ requirements cannot include sun exposure recommendations because public health concerns about skin cancer from sun exposure exclude this possibility (Ross, Taylor, Yaktine \& Del Valle, 2010). However, sunlight is an extremely important variable to consider as total body exposure to sun light may produce up to 10,000-20,000 IU (Holick, 2003). Even so, the committee decided the best approach was to estimate vitamin $D$ requirements assuming minimal sun exposure (Ross, Taylor, Yaktine \& Del Valle, 2010).

Secondly, vitamin $\mathrm{D}$ functions as a hormone regulated by metabolic feedback loops and has numerous nutrient interactions with calcium. Thus, distinguishing health outcomes for one nutrient and not the other presented a challenge (Ross, Taylor, Yaktine \& Del Valle, 2010).

The committee found that a level of $40 \mathrm{nmol} / \mathrm{L}$ was adequate to meet the needs of approximately half the population, otherwise known as the estimated average requirement (EAR) (Ross, Taylor, Yaktine \& Del Valle, 2010); while 50 $\mathrm{nmol} / \mathrm{L}$ was the level determined to be adequate to cover nearly the entire population (i.e. the RDA) (Ross, Taylor, Yaktine \& Del Valle, 2010). From the prior guidelines established in 1997, the DRI for vitamin D tripled from 200 IU to 600 IU/day (1-70 years of age) (Ross, Taylor, Yaktine \& Del Valle, 2010). 
Setting the new UL for vitamin D was especially challenging because data on the long term use of high levels of vitamin D was lacking, however the committee examined the existing data and followed an approach that would maximize public health protection (Ross, Taylor, Yaktine \& Del Valle, 2010). The observation that $10,000 \mathrm{IU}$ of vitamin D per day was not associated with classic toxicity served as the starting point for adults. The UL for vitamin D was increased from 2,000 IU/day to 4,000 IU/day in individuals $>9$ years of age (Ross, Taylor, Yaktine \& Del Valle, 2010) (Table 4). 
Table 4: Vitamin D Dietary Reference Intakes by Life Stage (amount/day)

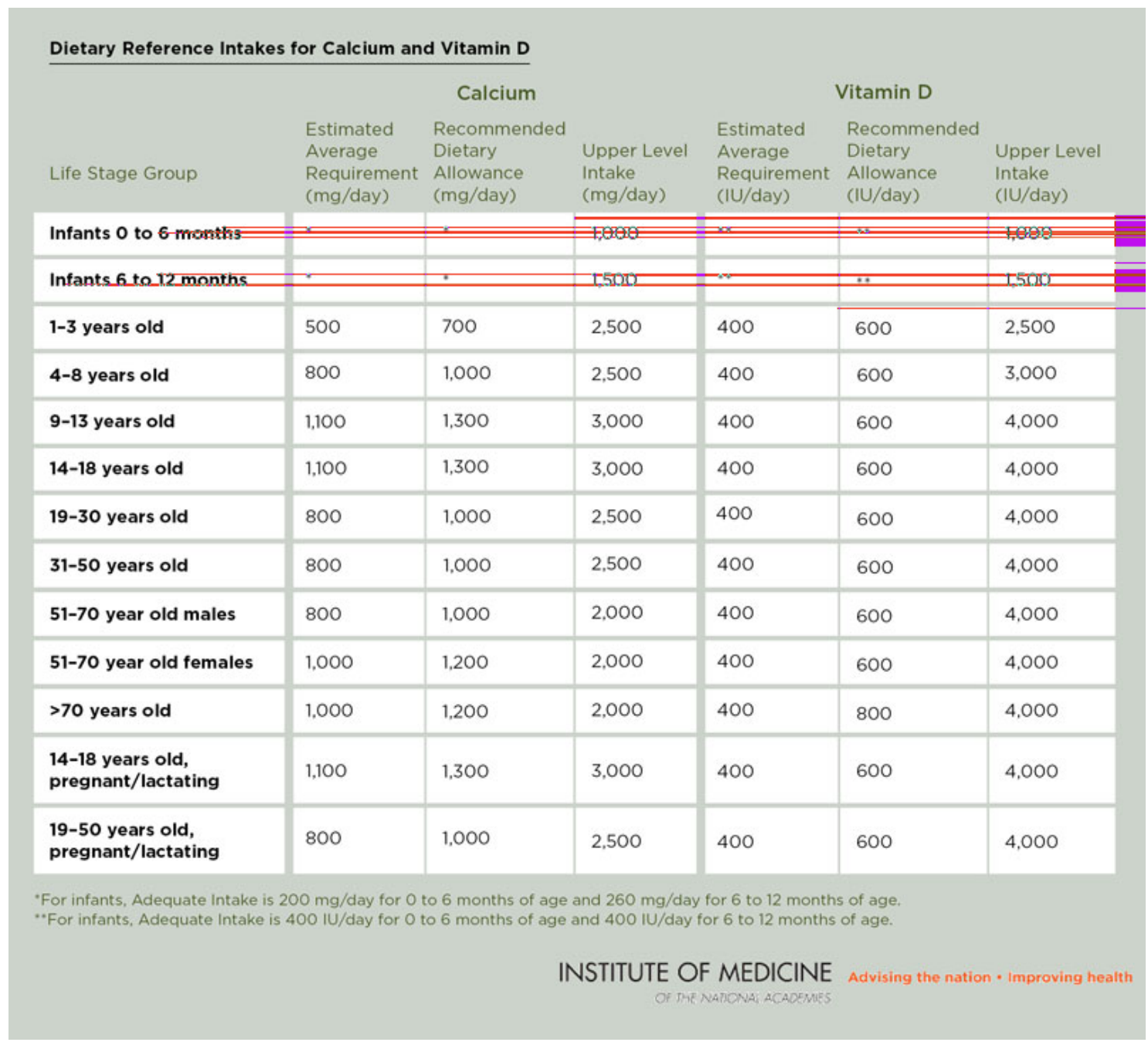

NOTE: $\mathrm{Al}=$ Adequate Intake; $\mathrm{EAR}=$ Estimated Average Requirement; IU = International Units; RDA = Recommended Dietary Allowance; UL = Tolerable Upper Intake Level.

Institute of Medicine, 2009.

\section{Measuring Sun Exposure}

There are several ways to measure sun exposure using daily sun logs/diaries, recall questionnaires, and/or dosimeter badges. Hall et al. (2010) used validated polysulphone (PS) dosimeter badges, in conjunction with daily sun exposure logs to determine whether or not sun exposure logs could 
accurately measure sun exposure (Hall et al., 2008). The daily sun exposure logs quantified time outside, joules of sun exposure, and helped calculate a sun exposure index (SEI) which incorporated time outside and body surface area (BSA) exposed. These measurements were compared to the PS dosimeter badges, an objective measure of sun exposure, worn by each participant throughout the study. All three measurements of sun exposure were found to be significant predictors of serum 25(OH)D $(p<0.05)$, however, joules of sun exposure and the SEI were significantly better predictors of serum $25(\mathrm{OH}) \mathrm{D}$ than time spent outside. Hall et al. (2010) demonstrated that sun exposure can be accurately assessed using simple methods.

Sullivan et al. (2003) also found that self-reported sun exposure was able to accurately capture actual sun exposure. This study had young girls keep track of their outdoor activities for one day, as well as wear a PS dosimeter badge. They found a significant correlation between the PS dosimeter badge and selfreported minutes outdoors adjusted for time of day $(r=0.64)$. Self-reported sun exposure accurately reflected actual sun exposure. 


\section{Conclusion}

Vitamin D deficiency appears to be a growing epidemic (Bang, 2009) and is associated with many acute and chronic health complications (Holick, 2004a) contributing to a substantial economic burden (Bueno \& Czepielewski, 2008). Although this vitamin is uniquely synthesized from exposure to sunlight, many environmental and individual-level factors alter the individual's ability to receive sufficient vitamin $D$ from sunlight. At the same time, vitamin $D$ is also not naturally found in many foods.

Vitamin D has a known role in bone health, regulation of many cells, control of over 200 genes and is linked to the prevention of multiple chronic diseases (IOM, 2010). The DRI guidelines for vitamin D tripled from 200 IU to 600 IU/day (1-70 years old) in 2010 from the original guidelines set in 1997 without a consideration of sun exposure. It is crucial to better understand the impact of sun exposure on vitamin D status, and identify the most accurate, least expensive and nonburdensome tools with which to collect this information. Little has been published about the vitamin D status of college students, therefore the present study sought to explore the determinants of vitamin D status (i.e. serum $25(\mathrm{OH}) \mathrm{D}$ ) in college students as part of a larger cohort. 


\section{Materials and Methods}

\section{Study Design of The FLASH Study}

The Following the Longitudinal Aspects of Student Health (FLASH) Study is an epidemiologic investigation into the health status, health behaviors, and health perceptions of college students attending California Polytechnic State University (Cal Poly, $35.3^{\circ} \mathrm{N}$ ). The first component was an online survey administered to 3,800 incoming freshmen (fall 2009) with questions regarding health perceptions, lifestyle habits, physical activity, stress, dietary habits, sun exposure and sunscreen use. The FLASH questionnaire also included questions about sun exposure (weekday/weekend), frequency of milk intake, dietary supplements and frequency of fish intake.

The second component of the FLASH Study included a physical assessment recording height, weight, estimated body composition, waist circumference, resting blood pressure and pulse rate. A third component included the vitamin $\mathrm{D}$ analysis consisting of a blood draw, vitamin $\mathrm{D}$ specific food frequency recall questionnaire, 28-day sun exposure recall questionnaire and skin reflectance measurements in a subset of participants.

\section{Study Design of Vitamin D Subset Study}

The vitamin D assessment was a longitudinal study conducted at two time points, spring 2010 (Visit 1) and fall 2010 (Visit 2). Visit 1 measurements were taken freshman year, April-May (after winter months), and Visit 2 measurements were taken sophomore year, September-October (after summer months). Forty eight participants were initially recruited from the FLASH Study to participate in 
the Vitamin D assessment and 45 of those participants completed the original online FLASH Questionnaire (Visit 1). For Visit 2, 40 of those participants returned for the vitamin $\mathrm{D}$ assessment and 35 of those participants completed the original online FLASH Questionnaire (Figure 5). Therefore, full data sets are presented for Visit 1 and compared to the available data for Visit 2 (Table 5).

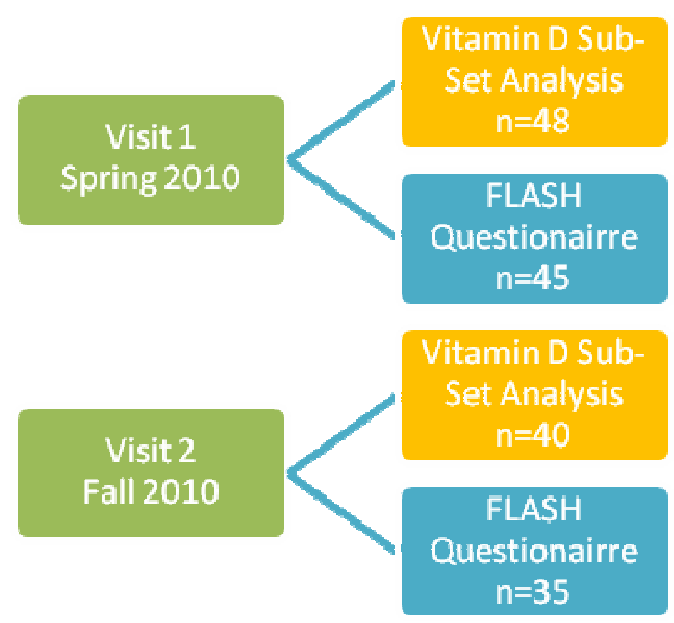

Figure 5: Visit 1 and Visit 2 data collection from Vitamin $D$ assessment and FLASH study.

\section{Participants}

Participants enrolled in the vitamin D assessment were freshmen students that previously completed the online FLASH questionnaire and physical assessment. Inclusion criteria included: BMI $18.5-30 \mathrm{~kg} / \mathrm{m}^{2}$, general good health and willingness to follow the study protocol. General good health was defined by no liver or kidney disease, fat malabsorption or diabetes. Exclusion criteria included: use of tanning beds or high-dose vitamin D supplements (excluding RDA level multivitamin supplements) within 2 months of enrollment, pregnancy, and presence of any disease, condition, or use of medication that might affect 
vitamin D metabolism, such as chronic kidney disease or liver disease. Oral contraceptive users were not excluded. The study was approved by the Cal Poly Human Subjects Committee. We determined that the study needed 30 participants to detect a significant change in $25(\mathrm{OH}) \mathrm{D}$ status from spring to fall based on sample size calculations using previous data (Hall et al., 2010) with a power of 0.8 and $\alpha=0.05$.

\section{Study Hypothesis and Specific Objectives}

The FLASH Vitamin D study hypothesized that sun exposure recall questionnaires, food frequency questionnaires specific to vitamin $D$ intake and skin reflectance measurements would predict individual serum $25(\mathrm{OH}) \mathrm{D}$ status.

The FLASH Vitamin D Study had four specific objectives. The first was to determine overall vitamin $D$ status in the population of participants. The second was to describe the variation in sun exposure, skin pigment and dietary vitamin $D$ intake within the study population. The third was to develop a regression model using sun exposure, skin pigment and dietary vitamin $D$ intake to predict vitamin D status. The fourth was to test which variables best predict vitamin D status in the regression model using different tools. These tools included recall questionnaires as well as specific sun and diet questions from the FLASH Questionnaire.

\section{Serum 25(OH)D}

Blood samples $(5 \mathrm{~mL})$ were taken at the Cal Poly Health Center in the spring and fall of 2010 after a 12 hour fast. Samples were sent to the local 
Central Coast Pathology Lab where 25(OH)D was measured by an IDS-iSYS Immunodiagnostic System.

\section{Sun Exposure Assessment}

Sun exposure was measured in the spring and fall 2010 via the FLASH questionnaire and a sun exposure 28-day recall questionnaire. The FLASH questionnaire was administered online with categorical questions regarding sun exposure and sunscreen use (Table 6). Participants were asked to classify their typical sun exposure as high or low, amount of time spent in the sun on weekdays, amount of time spent in the sun on weekends, the parts of body exposed when in the sun and typical sunscreen use. The weekday and weekend sun exposure questions asked participants to quantify minutes in the sun per day into four categories: $<30$ minutes, 30-59 minutes, $60-90$ minutes or $>90$ minutes. Participants were then asked to record the parts of their body that were exposed to the sun when outside including: face, neck, shoulders, back, upper arms, lower arms, hands, stomach, upper thighs, lower legs, or feet (Figure 6). Participants were asked to quantify typical sunscreen use into one of four categories: rarely or never applying sunscreen, applying sunscreen only when outdoors for extended periods of time, applying sunscreen when outdoors, or always applying sunscreen.

The second sun exposure assessment tool was a 28-day recall questionnaire administered prior to their blood draw, in which participants were asked to recall the time of day in the sun, minutes in direct sunlight, activity, location, clothing worn/body surface area (BSA) exposed and sunscreen use 
each day as previously validated by Hall et al. (2008). Previous assessments have used a sun exposure index (SEI) and have found it to be a more accurate marker of sun exposure than time outside (Barger-Lux \& Heaney, 2002). The SEI is calculated by multiplying time outside and BSA exposed (Barger-Lux \& Heaney, 2002 and Hall et al., 2010).

The 28-day recall questionnaire asked for participants minutes in the direct sun based on three time segments; 7am-11am, 11am-3pm and 3pm-7pm. A clothing key was used to accurately document the amount of clothing worn when outside (Figure 6). From the amount of clothing worn, estimates of BSA exposed to the sun was determined using an adjusted "rule of nines" (Hall et al., 2010) (Table 5). A Sun Exposure Index (SEI) was then used to determine the amount of sun exposure per day for each participant by multiplying BSA exposed by the minutes in direct sun (Barger-Lux \& Heaney, 2002 and Hall et al, 2010). An average SEI was determined for each day, while the participant's monthly average was used in analyses. Trained nutrition students helped the students fill out the questionnaire to obtain accurate data. 


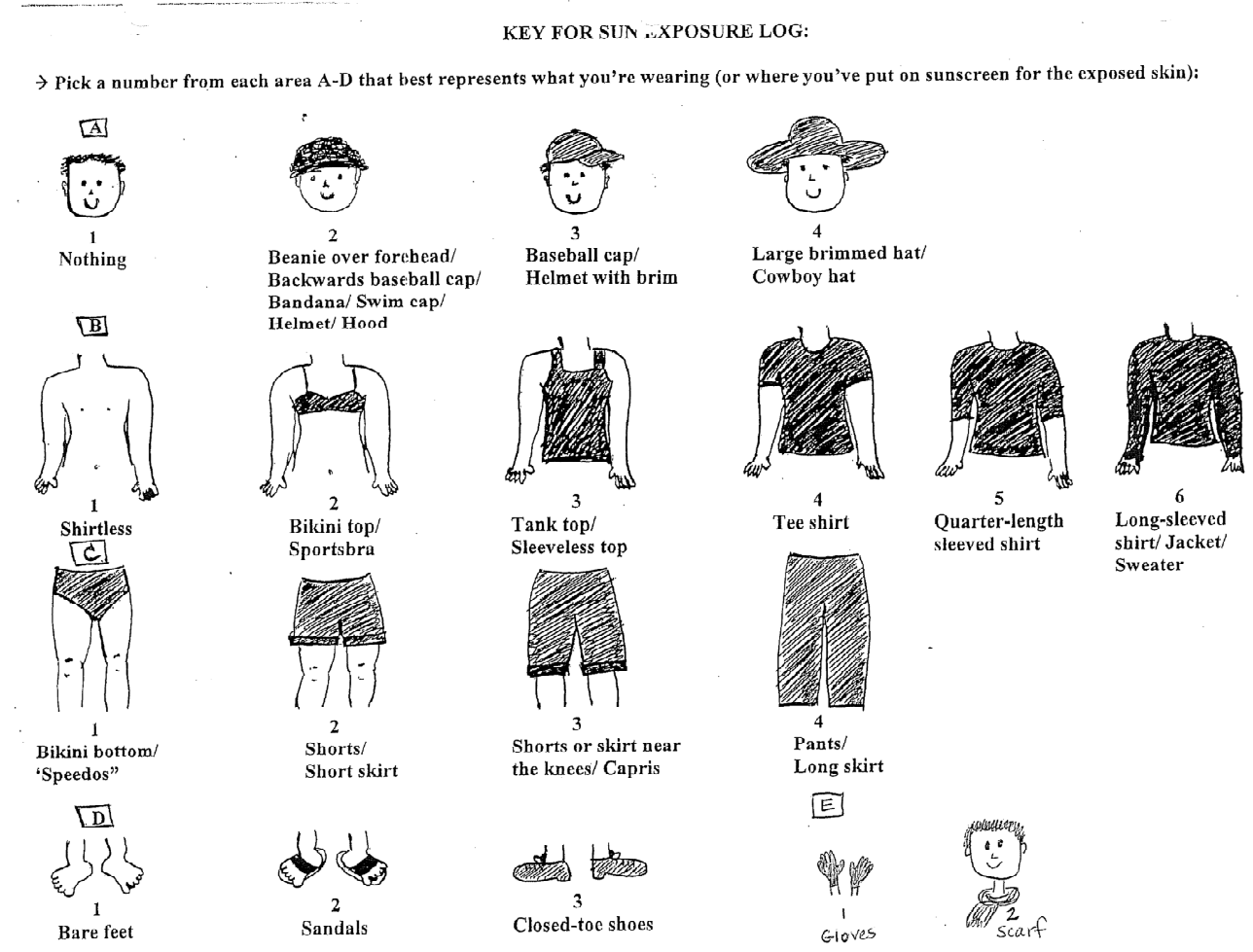

Figure 6: Sun Exposure Key was used by participants in study to document clothing worn. From clothing worn, an estimate of BSA exposed to the sun was determined using the "rule of nines" (Hall et al., 2010).

\section{Dietary Vitamin D Assessment}

Vitamin D intake was measured in the spring and fall of 2010 via the FLASH questionnaire and a 28-day vitamin D-specific dietary recall questionnaire. The FLASH questionnaire was administered online with questions regarding frequency of fish and milk intake. Participants were asked to categorize their fish and milk intake into one of the following groups: never, 1-3 times/week, 1-2 times/week, 3-4 times/week, 5-6 times/week, 1 time/day, and 2 times/day.

The second tool used was a 28-day recall questionnaire asking participants to record the frequency and intake of vitamin D specific foods as well as supplements (Hall et al., 2008) prior to their blood draw (see appendix). 
Trained nutrition students assisted participants when filling out the food frequency questionnaire by showing portion sizes, as well as measuring cups/spoons, to help attain accurate intake measurements. They also encouraged participants to keep similar dietary habits and eating patterns between assessments.

\section{Skin Reflectance Assessment}

Skin reflectance (pigmentation) was measured using a Minolta 2500d spectrophotometer (Konica Minolta Sensing) in the spring and fall of 2010 at the time of the participants blood draw. Measurements were taken on the middle right arm, the dorsum of the right hand between the thumb and index finger, and the middle of the forehead. Each site was measured 3 times and the mean number was used in the final analysis. The measurements were expressed in $L^{*}$ (lightness) value of the Commission International d'Eclairage System. The L*

value ranges from 0 to 100 , with 0 indicating no reflected light (pure black) and a value of 100 indicating $100 \%$ reflectance (pure white). The $L^{*}$ value is highly correlated to the Melanin Index (Matsuoka et al., 1992) and the $L^{*}$ value on the forehead was used in the multiple linear regression model because it was previously shown to be more correlated with serum $25(\mathrm{OH}) \mathrm{D}$ than the inner arm and hand measurements (Hall et al., 2010).

\section{Statistical Methods}

SAS version 9.1.3 (Sas Institute, Cary, NC) and MiniTab 16 (Minitab Inc., State College, PA) were used to perform the statistical analyses. Continuous data were tested for normality using the Kolmogorov-Smirnov test and variables 
not normally distributed were transformed using Box-Cox transformations.

Pearson correlations were used to examine correlations between variables. To predict serum $25(\mathrm{OH}) \mathrm{D}$ in the spring and fall, multiple linear regression was used with variables capturing sun exposure, vitamin D intake and skin pigmentation/reflectance because they influence vitamin D status. Measurements examined for sun exposure included time spent in the sun, SEI, sun level, BSA exposed, minutes in the sun (weekday or weekend), and sunscreen use. The dietary measurements for vitamin $D$ intake included average vitamin $D$ (IU/day) and frequency of participants' milk and fish intake. P-values $<0.05$ were considered significant.

Combinations of variables for sun exposure and vitamin D intake were entered into the model along with continuous variables for forehead skin reflectance. Only forehead skin reflectance was used because the arm and hand skin reflectance were not significant predictors. First, the continuous variables were examined using the average sun exposure index (SEI) and vitamin D intake (IU/day) from the 28-day recall questionnaires. These tools were examined first because they captured more data, then the vitamin $D$ intake and sun exposure data from the FLASH Questionnaire were incorporated into the model. All measurements were examined in the model. Every combination of variables for sun exposure and vitamin $D$ intake along with skin reflectance was systematically examined to determine the best predictors of vitamin D status and ultimately identify the most useful tools to use to capture this data. 


\section{$\underline{\text { Results }}$}

\section{Characteristics of Study Participants}

In the spring (Visit 1), 25 females and 23 males participated in the vitamin D specific assessment $(n=48)$, while in the fall (Visit 2) 23 females and 17 males completed the assessment $(n=40)$. The BMI for these 40 participants was $23.3 \pm$ $3.6 \mathrm{~kg} / \mathrm{m}^{2}$ (mean $\pm \mathrm{SD}$ ) (Table 5).

Table 5: Characteristics of Study Participants along with Vitamin D Intake, Time Spent in the Sun, Sun Exposure Index, Serum 25(OH)D and Forehead Skin Pigmentation (mean $\pm S D)$

\begin{tabular}{|l|c|c|c|c|}
\hline & Visit 1 (Total) $^{1}$ & Visit 1 $^{2}$ & Visit 2 $^{3}$ & P-Value $^{4}$ \\
\hline Participants (n) & 48 & 40 & 40 & \\
\hline BMI $\left(\mathrm{kg} / \mathrm{m}^{2}\right)$ & $23.4 \pm 3.4$ & $23.3 \pm 3.6$ & $23.3 \pm 3.6$ & \\
\hline Females & 25 & 23 & 23 & \\
\hline Males & 23 & 17 & 17 & \\
\hline Vit D Intake (IU) & $298.3 \pm 219.6$ & $308.3 \pm 234.3$ & $316.8 \pm 256.9$ & 0.8282 \\
\hline Time (mins) & $75.1 \pm 42.3$ & $80.7 \pm 44.0$ & $75.9 \pm 38.6$ & 0.5123 \\
\hline SEI (BSA x mins) & $51.8 \pm 38.2$ & $53.4 \pm 38.3$ & $54.6 \pm 34.0$ & 0.8476 \\
\hline 25(OH)D (nmol/L) & $84.5 \pm 23.7$ & $85.4 \pm 24.3$ & $112.9 \pm 27.9$ & $<0.0001$ \\
\hline Skin (L*) & $61.3 \pm 3.4$ & $61.5 \pm 3.5$ & $60.6 \pm 4.3$ & 0.1244 \\
\hline
\end{tabular}

${ }^{1}$ Visit 1 all participants' data collected April-May $2010(n=48)$

${ }^{2}$ Visit 1 participants' data collected April-May 2010 that returned for visit $2(n=40)$

${ }^{3}$ Visit 2 participants' data collected September-November 2010 that returned for Visit $2(n=40)$

${ }^{4}$ Significant $p$-value $<0.05$ between Visit 1 and Visit 2 measurements using a paired t-test in the 40 participants who completed both Visits

${ }^{5} \mathrm{IU}$ indicates the average dietary vitamin D and supplement intake/day

${ }^{6}$ Time is the average time spent in sun/day in minutes

${ }^{7} \mathrm{SEl}$ is the average Sun Exposure Index per day (body surface area exposed $x$ minutes in sun)

${ }^{8} 25(\mathrm{OH}) \mathrm{D}$ is the average serum 25 -hydroxyvitamin $\mathrm{D}$ as measured by an IDS-

iSYS Immunodiagnostic System at Central Coast Pathology

${ }^{9} L^{*}$ average forehead $L^{*}$ (lightness) skin reflectance per participant 


\section{Sociodemographic Data}

The FLASH Questionnaire collected information regarding race/ethnicity, highest level of parental education and parental annual income. The majority of the participants were white (88\%), while one participant was mixed race nonHispanic (3\%), one participant was Asian (3\%) and two participants were Hispanic of any race (6\%) (Table 6). All the participants' mothers graduated high school, and the majority of participants' mothers graduated college (63\%) (Table 6). Only one participant's father did not graduate high school (3\%), while the majority of participants' fathers graduated college (40\%) or graduate school (20\%). Most participants' mothers earned $\$ 25,000$ to $\$ 49,999$ per year $(28 \%)$ or $\$ 50,000$ to $\$ 74,999$ per year (18\%), while none earned $>\$ 100,000$ per year (Table 6). However, participants' fathers income level was considerably higher with nine fathers earning $\$ 50,000$ to $\$ 74,999$ (20\%), ten fathers earning $\$ 75,000$ to $\$ 100,000$ (23\%) and thirteen fathers earning $>\$ 100,000$ (30\%) (Table 6). 
Table 6: Sociodemographic Data from FLASH Questionnaire

\begin{tabular}{|c|c|}
\hline & [percent $(n)]$ \\
\hline \multicolumn{2}{|l|}{ Race/ethnicity $^{1}(n=34)$} \\
\hline Mixed Race, non-Hispanic & $3 \%(1)$ \\
\hline Asian, non-Hispanic & $3 \%(1)$ \\
\hline Black, African-American & $0 \%(0)$ \\
\hline Hispanic of any Race & $6 \%(2)$ \\
\hline White, non-Hispanic & $88 \%(30)$ \\
\hline \multicolumn{2}{|l|}{ Mother's Highest Education ${ }^{2}(\mathrm{n}=35)$} \\
\hline Not a high school graduate & $0 \%(0)$ \\
\hline Graduated high school & $6 \%(2)$ \\
\hline Attended some college & $20 \%(7)$ \\
\hline Graduated College & $63 \%(22)$ \\
\hline Completed graduate school & $11 \%(4)$ \\
\hline \multicolumn{2}{|l|}{ Father's Highest Education ${ }^{3}(\mathrm{n}=35)$} \\
\hline Not a high school graduate & $3 \%(1)$ \\
\hline Graduated high school & $17 \%(6)$ \\
\hline Attended some college & $20 \%(7)$ \\
\hline Graduated College & $40 \%(14)$ \\
\hline Completed graduate school & $20 \%(7)$ \\
\hline \multicolumn{2}{|l|}{ Mother's Income Level ${ }^{4}(n=43)$} \\
\hline No Income & $18 \%(8)$ \\
\hline$<\$ 10,000$ & $21 \%(9)$ \\
\hline$\$ 10,000$ to $\$ 24,999$ & $5 \%(2)$ \\
\hline$\$ 25,000$ to $\$ 49,999$ & $28 \%(12)$ \\
\hline$\$ 50,000$ to $\$ 74,999$ & $19 \%(8)$ \\
\hline$\$ 75,000$ to $\$ 100,000$ & $9 \%(4)$ \\
\hline$>\$ 100,000$ & $0 \%(0)$ \\
\hline
\end{tabular}




\begin{tabular}{|c|c|}
\hline Father's Income Level ${ }^{5}(\mathrm{n}=44)$ & \\
\hline No Income & $9 \%(4)$ \\
\hline$<\$ 10,000$ & $5 \%(2)$ \\
\hline$\$ 10,000$ to $\$ 24,999$ & $5 \%(2)$ \\
\hline$\$ 25,000$ to $\$ 49,999$ & $9 \%(4)$ \\
\hline$\$ 50,000$ to $\$ 74,999$ & $20 \%(9)$ \\
\hline$\$ 75,000$ to $\$ 100,000$ & $23 \%(10)$ \\
\hline$>\$ 100,000$ & $30 \%(13)$ \\
\hline
\end{tabular}

${ }^{1}$ Visit 1 race/ethnicity data for each participant collected from FLASH Questionnaire

${ }^{2}$ Visit 1 categorical question from FLASH Questionnaire regarding mother's highest level of education

${ }^{3}$ Visit 1 categorical question from FLASH Questionnaire regarding father's highest level of education

${ }^{4}$ Visit 1 categorical question from FLASH Questionnaire regarding mother's annual amount of income

${ }^{5}$ Visit 1 categorical question from FLASH Questionnaire regarding father's annual amount of income

\section{Serum 25(OH)D Measurements}

Serum 25(OH)D (nmol/L) levels significantly increased from Visit $1(85.4 \pm$ $24)$ to Visit $2(112.9 \pm 28)(n=40)$ (Table 5; Figure 7). Based on the serum 25(OH)D DRI guidelines, $50 \mathrm{nmol} / \mathrm{L}$ is considered adequate for bone health (FNIC, 2011) and 5\% of participants in Visit 1, and none in Visit 2 were considered inadequate. Serum $25(\mathrm{OH}) \mathrm{D}$ levels were adequate in both the spring and fall assessments while a higher serum $25(\mathrm{OH}) \mathrm{D}$ status was observed after the summer months (Figure 7). 


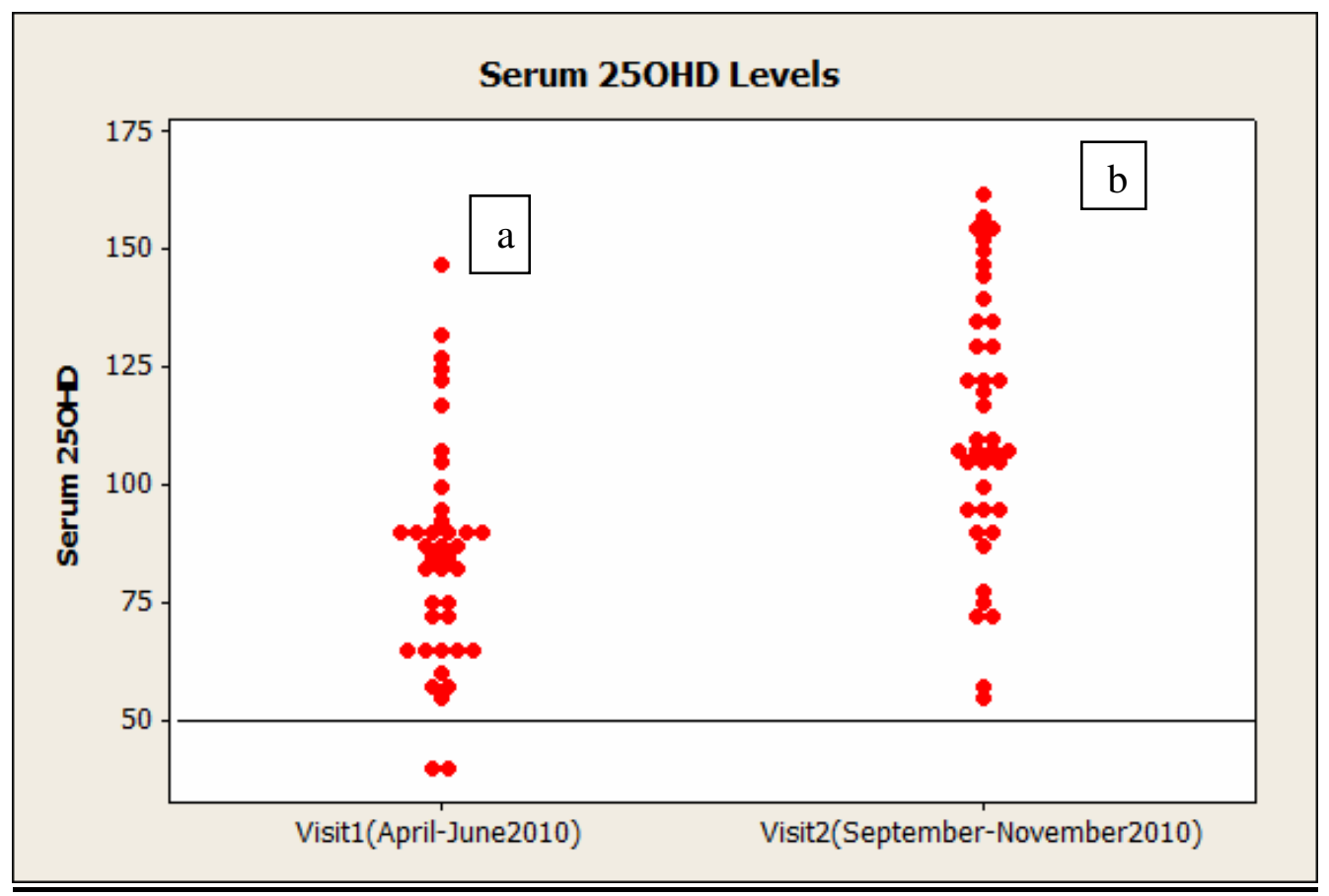

Figure 7: Individual serum 25(OH)D levels for Visit 1 and Visit $2(n=40)$. The line is set at $50 \mathrm{nmol} / \mathrm{L}$ which is considered adequate for bone health (FNIC, 2011). Different letters represent a significant difference in status.

\section{Sun Exposure}

\section{FLASH Sun Exposure Results}

Fifty-seven percent of participants characterized their sun exposure high in Visit 1, and this percentage increased to $63 \%$ of participants in Visit 2 (Table 7). Body surface area (BSA) exposed to the sun was similar for Visit $1(32 \% \pm$ 16) and Visit $2(32 \% \pm 17)$.

For weekday sun exposure during Visit 1, $8 \%$ of the participants recorded their typical sun exposure $<30$ minutes/day, $40 \%$ of the participants recorded sun exposure 30-59 minutes/day, $28 \%$ of the participants recorded sun exposure $60-90$ minutes/day, and $23 \%$ of the participants recorded sun exposure $>90$ minutes/day. For weekday sun exposure during Visit 2, 3\% of the participants recorded their typical sun exposure $<30$ minutes/day, $26 \%$ of the participants 
recorded sun exposure 30-59 minutes/day, $63 \%$ of the participants recorded sun exposure $60-90$ minutes/day, and $8 \%$ of the participants recorded sun exposure $>90$ minutes/day (Table 7). A decrease in participant's sun exposure $>90$ minutes/day was observed from Visit 1 with $23 \%$, to Visit 2 with $8 \%$. However, the largest variation between Visits was observed in the 60-90 minute/day category with $28 \%$ of participants in Visit 1 and $63 \%$ of participants in Visit 2 (Table 7).

For weekend sun exposure during Visit 1, $3 \%$ of the participants recorded sun exposure $<30$ minutes/day, $20 \%$ of the participants recorded sun exposure 30-59 minutes/day, $20 \%$ of the participants recorded sun exposure $60-90$ minutes/day, and $57 \%$ of the participants recorded sun exposure $>90$ minutes/day (Table 7). For weekend sun exposure during Visit 2, none of the participants recorded sun exposure $<30$ minutes/day, $9 \%$ of the participants recorded sun exposure 30-59 minutes/day, 34\% of the participants recorded sun exposure $60-90$ minutes/day, and $57 \%$ of the participants recorded sun exposure $>90$ minutes/day (Table 7). Weekend sun exposure in the 30-59 minute category increased slightly from Visit 1 with $20 \%$ to Visit 2 with $34 \%$. However, there was not an increase in weekend sun exposure $>90$ minutes from Visit 1 with $57 \%$, to Visit 2 with $57 \%$.

For sunscreen use, $6 \%$ of the participants reported they always wore sunscreen in Visit 1, while $11 \%$ of the participants reported they always wore sunscreen in Visit 2 (Table 7). However, 37\% of participants reported they rarely 
or never wore sunscreen in Visit 1, while $51 \%$ of participants reported they rarely or never wore sunscreen in Visit 2.

Table 7: Sun Exposure and Sunscreen Use from FLASH Questionnaire [percent (n)]

\begin{tabular}{|c|c|c|c|}
\hline & Visit $1^{1}$ & Visit $1^{2}$ & Visit $2^{3}$ \\
\hline Participants (n) & 45 & 35 & 35 \\
\hline \multicolumn{4}{|l|}{ Typical Sun Exposure ${ }^{4}$} \\
\hline High & $51 \%(23)$ & $57 \%(20)$ & $63 \%(22)$ \\
\hline Low & $49 \%(22)$ & $43 \%(15)$ & $37 \%(13)$ \\
\hline \multicolumn{4}{|l|}{ Weekday Sun Exposure ${ }^{5}$} \\
\hline$<30$ minutes & $9 \%(4)$ & $8 \%(3)$ & $3 \%(1)$ \\
\hline 30-59 minutes & $45 \%(20)$ & $40 \%(14)$ & $26 \%(9)$ \\
\hline $60-90$ minutes & $24 \%(11)$ & $28 \%(10)$ & $63 \%(22)$ \\
\hline$>90$ minutes & $22 \%(10)$ & $23 \%(8)$ & $8 \%(3)$ \\
\hline \multicolumn{4}{|l|}{ Weekend Sun Exposure ${ }^{6}$} \\
\hline$<30$ minutes & $5 \%(2)$ & $3 \%(1)$ & $0 \%(0)$ \\
\hline 30-59 minutes & $20 \%(9)$ & $20 \%(7)$ & $9 \%(3)$ \\
\hline $60-90$ minutes & $20 \%(10)$ & $20 \%(7)$ & $34 \%(12)$ \\
\hline$>90$ minutes & $53 \%(24)$ & $57 \%(20)$ & $57 \%(20)$ \\
\hline Parts of Body Exposed ${ }^{7}$ & $31 \% \pm 16.5$ & $32 \% \pm 15.6$ & $32 \% \pm 17.2$ \\
\hline \multicolumn{4}{|l|}{ Sunscreen Use ${ }^{8}$} \\
\hline Rarely or Never & $42 \%(19)$ & $37 \%(13)$ & $51 \%(18)$ \\
\hline Outdoors Extended & $49 \%(22)$ & $51 \%(18)$ & $31 \%(11)$ \\
\hline When Outdoors & $4 \%(2)$ & $6 \%(2)$ & $6 \%(2)$ \\
\hline Always & $4 \%(2)$ & $6 \%(2)$ & $11 \%(4)$ \\
\hline
\end{tabular}

${ }^{1}$ Visit 1 participant's initial data collected from April-May $2010(n=45)$

${ }^{2}$ Visit 1 participant's initial data collected from April-May 2010 that returned for Visit $2(n=35)$

${ }^{3}$ Visit 2 participant's data collected September-November 2010 participants that returned for Visit $2(\mathrm{n}=35)$

${ }^{4}$ Typical sun exposure was classified as high or low

${ }^{5}$ Weekday sun exposure for the 30 days prior (minutes spent in the sun) 
${ }^{6}$ Weekend sun exposure for the 30 days prior (minutes spent in the sun)

${ }^{7}$ Parts of body exposed (mean $\pm S D$ ) for the 30 days prior including; face, neck, shoulder, back, upper arm, lower arm, hand, stomach, upper thighs, lower legs and feet

${ }^{8}$ Sunscreen use other than cosmetics, for the prior 30 days

\section{8-day Sun Exposure Recall: Time in the sun}

Participants' time in the sun (minutes) did not significantly differ between Visit $1(80.7 \pm 44)$ and Visit $2(75.9 \pm 39)(p=0.5123)($ Table 5). Time outside is commonly used as a marker for sun exposure (Hall et al., 2010), but minutes in the sun did not significantly correlate to serum 25(OH)D in Visit $1(n=48)(r=$ $0.18, p=0.2189)$ or Visit $2(n=40),(r=0.12, p=0.4771)$ (Table 5).

\section{Sun Exposure Index (SEI)}

Participants' average SEI (BSA x mins.) did not differ between Visit 1 $(53.4 \pm 38)$ and Visit $2(54.6 \pm 34)(p=0.8476)($ Table 5). Overall SEI $(7 \mathrm{am}-7 \mathrm{pm})$ was not significantly correlated to vitamin D status in the spring $(n=48, r=0.26$, $p=0.0731)$ or in the fall $(n=40, r=0.16, p=0.3190)$ however, the correlation was higher in the spring (Figure 8). Examining the three different time periods, the SEl from 11am-3pm was significantly correlated with serum 25(OH)D in the spring $(n=48, r=0.35, p=0.0200)$ but not the fall $(n=40, r=0.17, p=0.3000)$ (Figure 9). The SEI calculated from 7am-11am and from 3pm-7pm did not correlate with serum 25(OH)D in either Visit (data not shown). Thus, the SEI from 11am-3pm demonstrated the strongest correlation to serum $25(\mathrm{OH}) \mathrm{D}$ status in the spring assessment. 


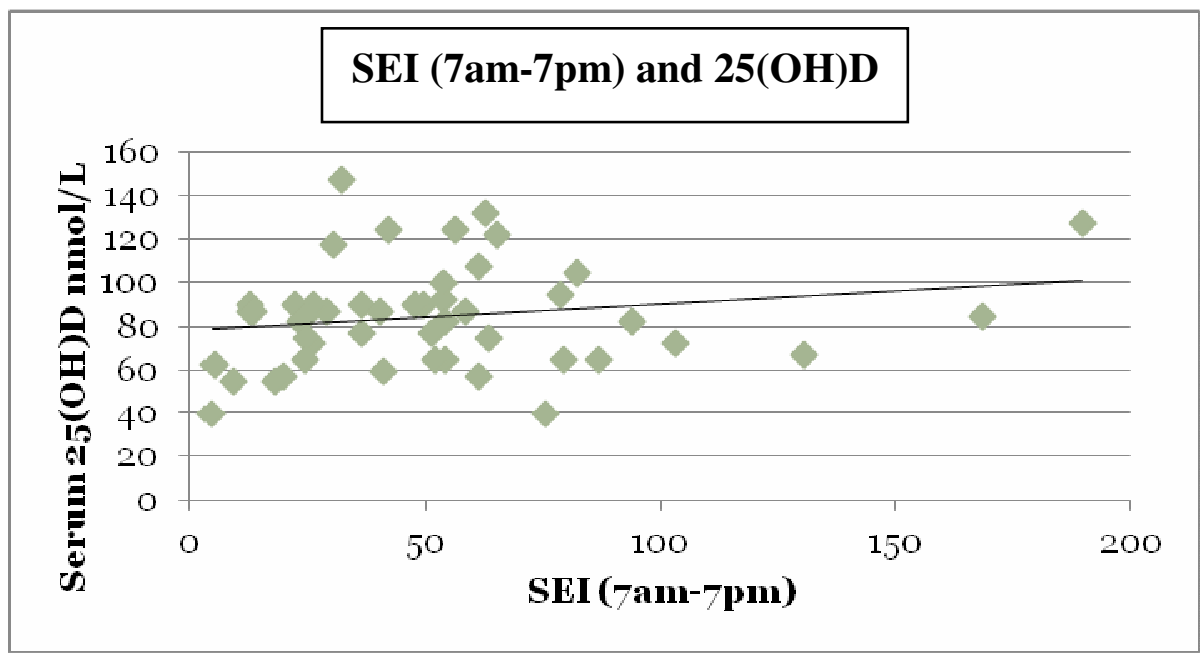

Figure 8: Correlation between the individual Sun Exposure Index (SEI) (BSA x mins) and serum 25-hydroxyvitamin D during Visit 1; 7am-7pm. ( $r=0.26$, $p=0.0731)$

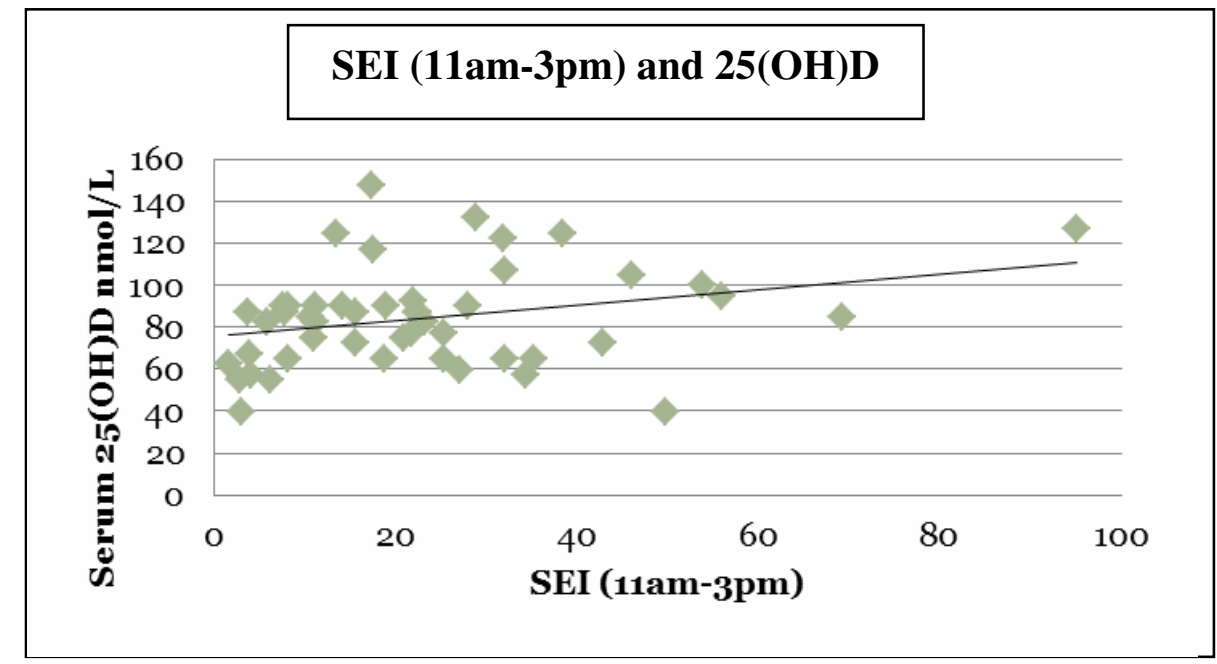

Figure 9: Correlation between the individual Sun Exposure Index (SEI) (BSA $x$ mins) and serum 25-hydroxyvitamin D during Visit 1; 11am-3pm. ( $r=0.35$, $p=0.0159)$ 


\section{Vitamin D Intake}

\section{FLASH Dietary Results}

The frequency of milk consumed per day increased from 14\% in Visit 1 to $26 \%$ in Visit 2; while the frequency of participant's fish consumption (1-3 times/month) decreased from $46 \%$ in Visit 1 to $37 \%$ in Visit 2 (Table 8).

Table 8: Dietary Information Related to Vitamin D Intake from FLASH Questionnaire [percent (n)]

\begin{tabular}{|c|c|c|c|}
\hline & Visit 1 $^{1}$ & Visit 1 $^{2}$ & Visit 2 $^{3}$ \\
\hline Participants (n) & 45 & 35 & 35 \\
\hline Frequency on Milk Intake & & & $11 \%(4)$ \\
\hline Never & $14 \%(6)$ & $17 \%(6)$ & $3 \%(1)$ \\
\hline $1-3$ times/ month & $23 \%(10)$ & $20 \%(7)$ & $20 \%(7)$ \\
\hline $1-2$ times/ week & $9 \%(4)$ & $9 \%(3)$ & $14 \%(5)$ \\
\hline $3-4$ times/ week & $18 \%(8)$ & $20 \%(7)$ & $20 \%(7)$ \\
\hline $5-6$ times/ week & $14 \%(6)$ & $11 \%(4)$ & $6 \%(2)$ \\
\hline 1 time/ day & $14 \%(6)$ & $14 \%(5)$ & $31 \%(11)$ \\
\hline 2 times/ day & $9 \%(4)$ & $9 \%(3)$ & $37 \%(13)$ \\
\hline Frequency of Fish Intake & & & $23 \%(8)$ \\
\hline Never & $34 \%(15)$ & $31 \%(11)$ & $9 \%(3)$ \\
\hline $1-3$ times/ month & $39 \%(17)$ & $46 \%(16)$ & $0 \%(0)$ \\
\hline $1-2$ times/ week & $23 \%(10)$ & $17 \%(6)$ & $3 \%(1)$ \\
\hline $3-4$ times/ week & $2 \%(1)$ & $3 \%(1)$ & \\
\hline $5-6$ times/ week & $2 \%(1)$ & & \\
\hline
\end{tabular}

${ }^{1}$ Visit 1 initial data collected from April-May $2010(n=45)$

${ }^{2}$ Visit 1 participants data collected from April-May 2010 that also completed survey in visit $2(\mathrm{n}=35)$

${ }^{3}$ Visit 2 data collected September-November 2010 for participants who completed survey for both visits $(n=35)$

${ }^{4}$ Frequency of milk intake for the past 30 days

${ }^{5}$ Frequency of fish intake for the past 30 days 


\section{Vitamin D Specific Food Frequency Questionnaire}

Participants reported a slight increase, although not statistically significant, in dietary vitamin $D(I U /$ day $)$ from Visit $1(308.3 \pm 243)$ to Visit $2(316.8 \pm 257)$, however, $90 \%$ of the participants in Visit 1 and $88 \%$ in Visit 2 did not meet the new RDA level of intake (Table 5; Figure 10). Despite the participants' low selfreported dietary intake, their serum $25(\mathrm{OH}) \mathrm{D}$ levels were adequate.

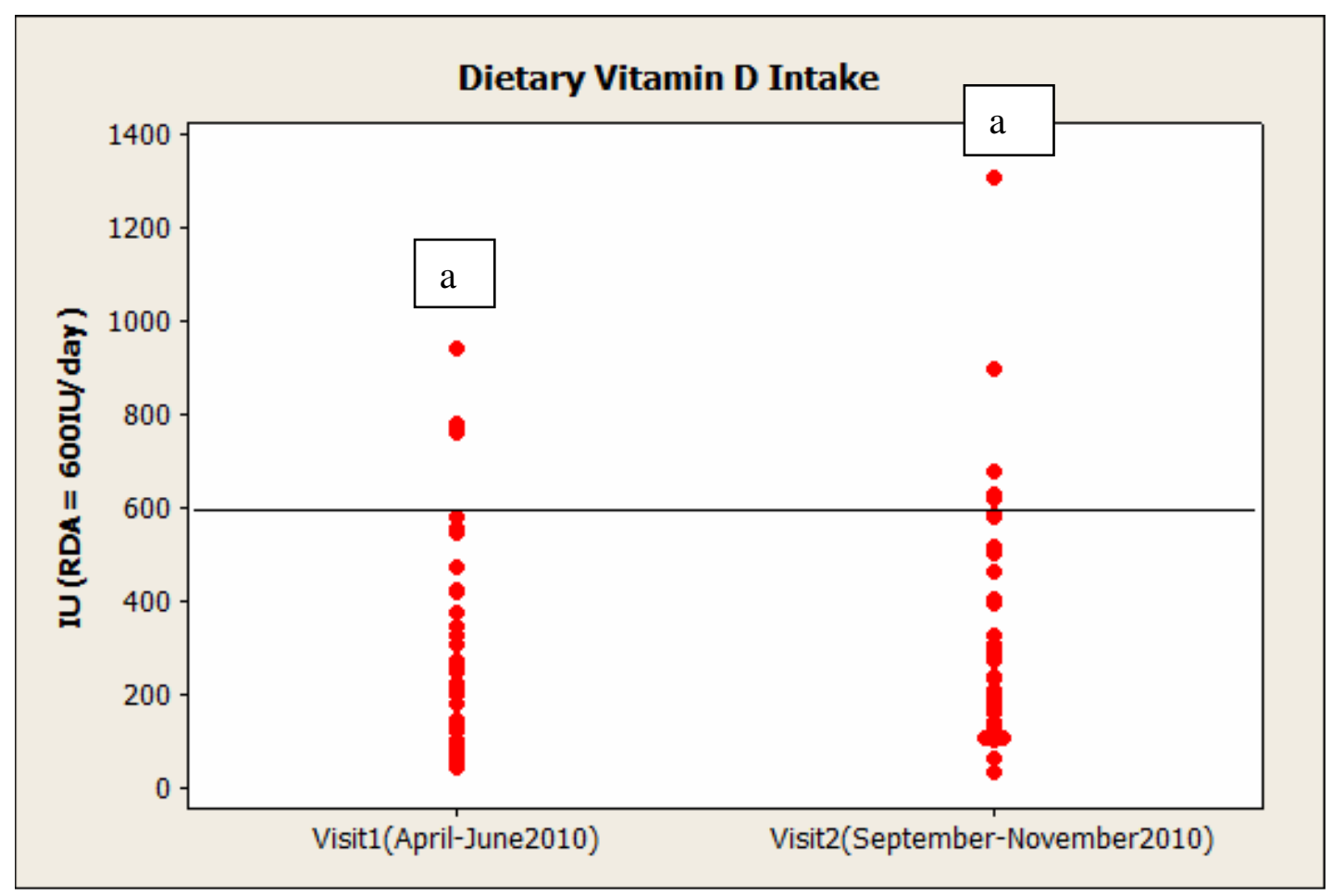

Figure 10: Individual vitamin $D$ intake (including food and supplements) during Visit 1 and Visit $2(n=40)$. The line represents the new RDA level of 600 IU/day (FNIC 2011). Different letters represent a significant difference in intake.

Participants dietary vitamin D intake, as measured by 28-day food frequency recall questionnaire, significantly correlated to serum 25(OH)D in Visit $1(r=0.32, p=0.0259)$ (Figure 11), but not Visit $2(r=-0.08, p=0.6428)$ (data not shown). 


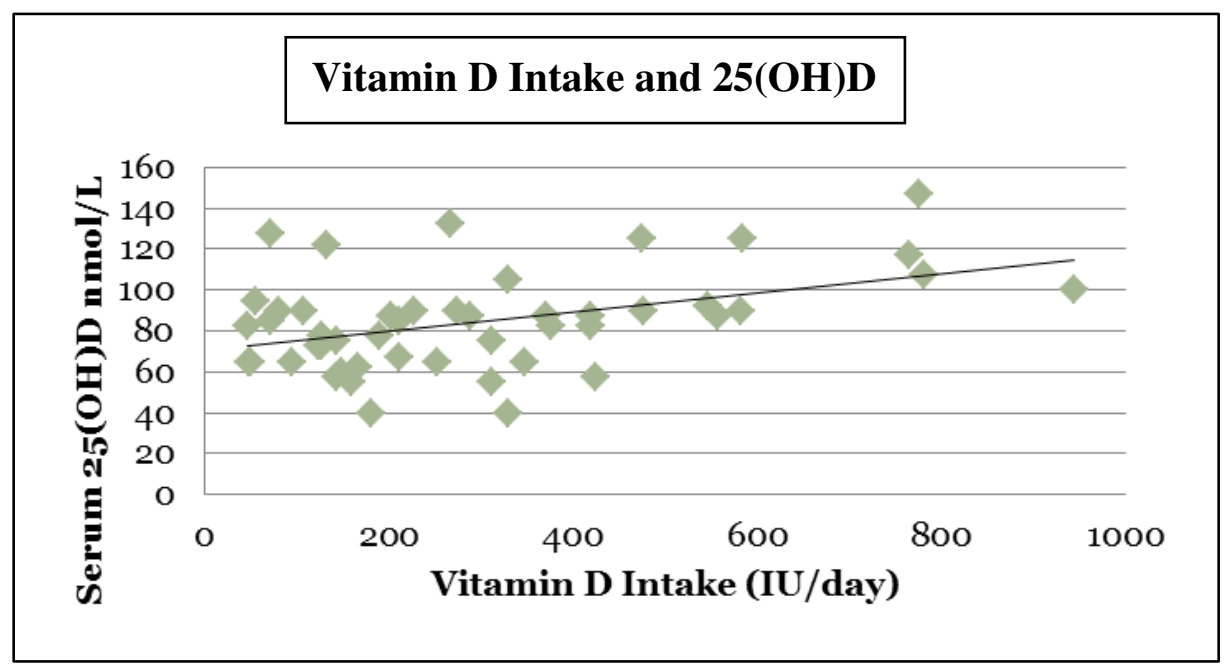

Figure 11: Correlation between the individual Vitamin $D$ Intake (IU/day) and serum 25(OH)D during Visit $1(r=0.32, p=0.0259)$

\section{Skin Reflectance (Pigmentation) Measurements}

Forehead skin reflectance measurements were not significantly different from each Visit (Table 5), but were significantly correlated with serum 25(OH)D in the spring $(n=48)(r=0.35, p=0.0140)$ (Figure 12) but not the fall $(n=40)(r=$ $0.17, p=0.2882)$. Neither the arm or hand measurement correlated to serum $25(\mathrm{OH}) \mathrm{D}$ in the spring nor fall (data not shown). 


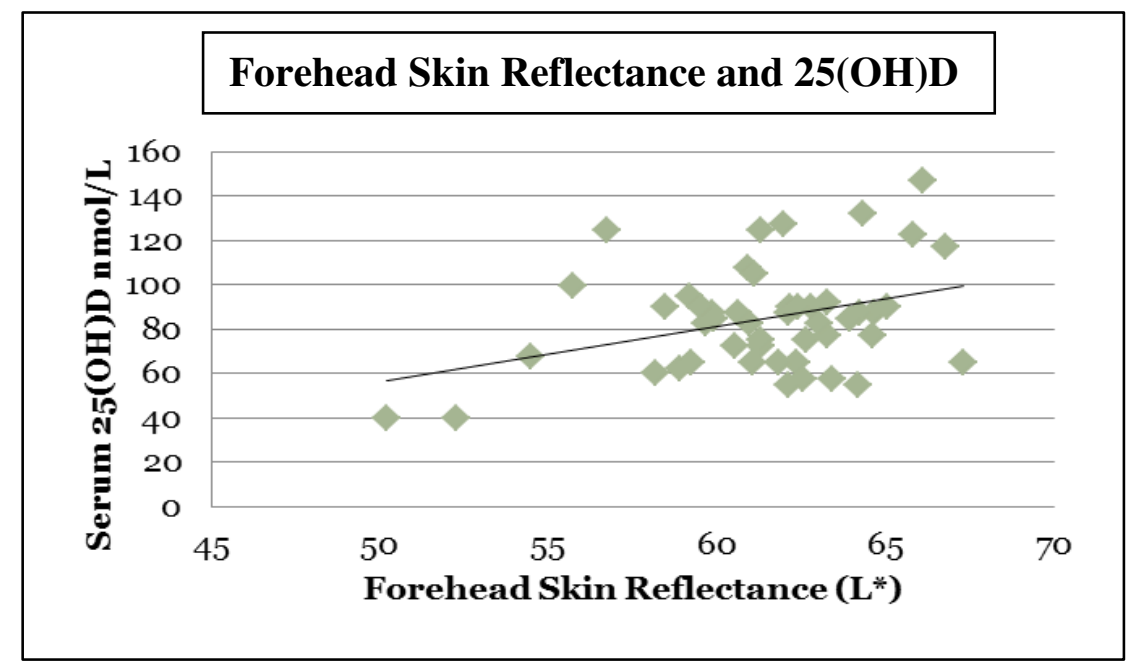

Figure 12: Correlation between the Forehead Skin Reflectance $\left(\mathrm{L}^{*}\right)$ and serum 25(OH)D during Visit $1(r=0.35, p=0.0140)$

\section{Models Predicting Serum 25(OH)D}

The average SEl from 7am-7pm (i.e. all day), average monthly intake of vitamin $D$, and average forehead skin reflectance in the spring model were significant predictors of serum $25(\mathrm{OH}) \mathrm{D}\left(\mathrm{R}^{2}=0.32, p=0.0007\right)$ (Table 9), but none of those variables were significant predictors of serum $25(\mathrm{OH}) \mathrm{D}$ in the fall model $\left(R^{2}=0.06, p=0.5331\right)$ (data not shown).

The average mid-day sun (i.e. SEI from 11am-3pm), average monthly intake of dietary vitamin $D$, and average forehead skin reflectance in the spring model were significant predictors of serum $25(\mathrm{OH}) \mathrm{D}\left(\mathrm{R}^{2}=0.34, p=0.0003\right)$ (Table 9), but none of those variables were significant in the fall model $\left(R^{2}=0.06\right.$, $\mathrm{p}=0.5150)$ (data not shown).

Weekend sun exposure (categorical), average monthly intake of vitamin D and average forehead skin reflectance in the spring model were significant predictors of serum $25(\mathrm{OH}) \mathrm{D}\left(\mathrm{R}^{2}=0.42, p=0.0005\right)$ (Table 9$)$, but none of those variables were significant in the fall model $\left(R^{2}=0.03, p=0.9386\right.$ ) (data not shown). Using participants' weekday sun exposure instead of weekend was not a 
significant predictor of status (data not shown); therefore self reported weekend sun exposure may be a better marker of typical sun exposure than weekday sun exposure.

The participants' average SEI for the time period of $11 \mathrm{am}-3 \mathrm{pm}$, fish intake (categorical), and average forehead skin reflectance in the spring model were significant predictors of serum 25(OH)D $\left(R^{2}=0.39, p=0.0036\right)$ (Table 9), but none of those variables were significant predictors in the fall model (data not shown). When milk intake (categorical) was used in the model instead of fish intake, it was not a significant predictor of vitamin D status (data not shown).

The participant's weekend sun exposure, fish intake, and average forehead skin reflectance in the spring model were significant predictors of serum $25(\mathrm{OH}) \mathrm{D}\left(\mathrm{R}^{2}=0.50, \mathrm{p}=0.0010\right)$ (Table 9), but none of those variables were significant predictors the fall model $\left(R^{2}=0.13, p=0.6609\right)$ (data not shown).

Other variables tested in the full regression model (i.e. model 5) were sun level, BSA, sunscreen, athlete and BMI, however none of these were significant predictors of vitamin D status in our population of participants (data not shown).

Sociodemographic variables from Table 6 were also tested in the full regression model (i.e. model 5), however none of the variables were significant predictors of serum 25(OH)D status in the spring (Visit 1) or fall (Visit 2). These included: gender $\left(R^{2}=0.52, p=0.2521\right)$ age $\left(R^{2}=0.50, p=0.7932\right)$, race/ethnicity $\left(R^{2}=0.49, p=0.6455\right)$, mother's education level $\left(R^{2}=0.48, p=0.9714\right)$, father's education level $\left(R^{2}=0.56, p=0.5818\right)$, mother's income level $\left(R^{2}=0.54, p=\right.$ 
$0.8550)$, father's income level $\left(R^{2}=0.60, p=0.3817\right)$ and $B M I\left(R^{2}=0.51, p=\right.$ 0.5421 ) (data not shown).

Table 9: Models Comparing Different Measures of Sun Exposure, Diet and Skin Pigment to Predict Vitamin D Status

\begin{tabular}{|c|c|c|c|}
\hline Model & $\mathrm{p}$-value & $\mathrm{R}^{2}$ & $\mathrm{p}$-value \\
\hline Model 1 & $0.0007^{*}$ & 0.32 & 0.0007 \\
\hline SEl (7am-7pm) & \multicolumn{1}{|c|}{} & \\
\hline Vit D Intake (IU) $^{2}$ & $0.0155^{*}$ & & \\
\hline Skin Reflectance (forehead) $^{3}$ & $0.0123^{*}$ & & \\
\hline Model 2 & $0.0041^{*}$ & & \\
\hline SEl (11am-3pm) & $0.0003^{*}$ & 0.34 & 0.0003 \\
\hline Vit D Intake (IU) & $0.0064^{*}$ & & \\
\hline Skin Reflectance (forehead) & $0.0118^{*}$ & & \\
\hline Model 3 & $0.0077^{*}$ & & \\
\hline SEl (11am-3pm) & $0.0036^{*}$ & 0.39 & 0.0036 \\
\hline Fish Intake & $0.0230^{*}$ & & \\
\hline Skin Reflectance (forehead) & $0.0193^{*}$ & & \\
\hline Model 4 & $0.0033^{*}$ & & \\
\hline Weekend Sun Exposure & $0.0005^{*}$ & 0.42 & 0.0005 \\
\hline Vit D Intake (IU) & $0.0104^{*}$ & & \\
\hline Skin Reflectance (forehead) & $0.0236^{*}$ & & \\
\hline Model 5 & $0.0095^{*}$ & & \\
\hline Weekend Sun Exposure & $0.0010^{*}$ & 0.50 & 0.0010 \\
\hline Fish Intake & $0.0075^{*}$ & & \\
\hline Skin Reflectance (forehead) & $0.0119^{*}$ & & \\
\hline
\end{tabular}

${ }^{*}$ Significant $p$-value $<0.05$

${ }^{1} \mathrm{SEI}=$ mean sun exposure index includes minutes in direct sun $\times$ BSA exposed/ subject using 28-day recall questionnaire from $7 \mathrm{am}-7 \mathrm{pm}$ or $11 \mathrm{am}-3 \mathrm{pm}$

${ }^{2} \mathrm{IU}=$ mean vitamin $\mathrm{D}$ intake including supplements per subject using 28-day recall questionnaire

${ }^{3}$ Forehead $=$ mean forehead $L^{*}$ skin reflectance per subject

${ }^{4}$ Fish intake = average frequency of intake using FLASH questionnaire

${ }^{5}$ Weekend Sun Exposure = average reported time spent outside on the weekends using categories from FLASH questionnaire 


\section{Discussion}

The present study found that $90 \%$ of the participants in Visit 1 and $88 \%$ in Visit 2 did not meet the current RDA for dietary vitamin D intake (600 IU/day) (1$70 \mathrm{yrs}$ of age) (FNIC, 2011). Despite the participants reporting low dietary and supplemental intake of vitamin $\mathrm{D}$, only $5 \%$ had serum $25(\mathrm{OH}) \mathrm{D}$ levels below the recommended cut off of $<50 \mathrm{nmol} / \mathrm{L}$ in spring 2010 of their Freshman year (Visit 1), and none were inadequate in fall 2010 of their Sophomore year (Visit 2). Participants likely attained adequate serum 25(OH)D from sun exposure considering that Cal Poly is near the in the central coast of California $\left(35.3^{\circ} \mathrm{N}\right)$ with moderate weather year around. Findings in the present study were consistent with national survey data (IOM, 2010) as it was reported most people, in the United States and Canada, have an average serum 25(OH)D below $<50$ $\mathrm{nmol} / \mathrm{L}$. This national survey also found subgroups, particularly older individuals living in institutions or individuals with darker skin pigmentation were at an increased risk for low serum $25(\mathrm{OH}) \mathrm{D}$, and is likely from inadequate sun exposure (IOM, 2010).

Despite current literature stating that the majority of Americans are deficient in vitamin D (IOM, 2010), Hall et al. (2010) and the present study found the majority of their college-aged participants to have adequate serum $25(\mathrm{OH}) \mathrm{D}$ levels as well as an overall better vitamin D status than the average American (IOM, 2010).

Although sun exposure is an important contributor to vitamin D status (i.e. serum $25(\mathrm{OH}) \mathrm{D}$ ), it is difficult to quantify. McCarthy (2008) found that individual- 
level sun exposure data was more accurate than environmental measurements of sun exposure because participants' sunscreen use and sun behavior practices were more important determinants of status (McCarthy, 2008). Collecting data on the individual factors contributing to sun exposure is extremely challenging, along with environmental influences, and the best methods have not yet been determined. However, Hall et al. (2010) found that daily sun exposure logs assessing time outside and clothing worn accurately captured sun exposure as compared to an objective measure of sun exposure, polysulphone (PS) dosimeter badges. Hall et al. (2008) also validated sun exposure recall questionnaires against the daily sun logs and found that they also accurately captured individual-level sun exposure demonstrating the usefulness of simple tools. Sullivan et al. (2003) also found that self-reported sun exposure-accurately captured actual sun exposure. The present study was designed to determine the effectiveness of previous validated questionnaires (Hall et al., 2008) and a simple categorical questionnaire to assess participants' sun exposure.

A 28-day sun exposure recall questionnaire was administered during this study and measured time of day, minutes in sunlight and clothing worn. Time spent in the sun (minutes) was not a significant predictor of serum $25(\mathrm{OH}) \mathrm{D}$ status, however, SEI (BSA x min) was significant. This reemphasized the importance of assessing BSA exposed to the sun, rather than just time spent in the sun. Minutes alone has not been a significant predictor of $25(\mathrm{OH}) \mathrm{D}$ in other studies as well. For example, in the Netherlands, a northern latitude with limited

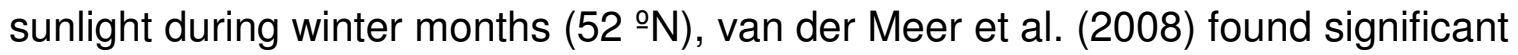


associations between season, area of uncovered skin and preference for the sun, but not for time spent outdoors. Van der Meer (2008) proposed that the effect of clothing and skin pigmentation might overrule the variable of time spent outdoors.

The present study also found that the overall SEI from $7 \mathrm{am}-7 \mathrm{pm}$ did not significantly correlate to vitamin $D$ status in the spring $(r=0.26, p=0.0731)$ (Figure 8), however, the mid-day SEI from 11am-3pm significantly correlated with serum $25(\mathrm{OH}) \mathrm{D}$ in the spring $(r=0.35, p=0.0159)$ (Figure 9). Narrowing the SEI (11am-3pm) captured the time of the day when UVB radiation was the strongest and when the individual was more likely to synthesize vitamin D. Future studies may only need to assess this narrow time frame.

Serum 25(OH)D significantly increased from Visit 1 to Visit 2, without a significant increase in sun exposure or dietary intake as measured by the recall questionnaires (Table 9). On the other hand, participants who characterized their typical sun exposure as high in Visit 1 (57\%) increased in Visit 2 (63\%) (Table 7). This incremental difference in typical sun exposure may be because the participants spent more time outside during the summer, thus, considering themselves to also have high sun exposure during the fall (Visit 2). From the FLASH Questionnaire, the largest variation between visits was observed in the daily sun exposure category of $60-90$ minute/day with $28 \%$ of participants in Visit 1 and $63 \%$ of participants in Visit 2 considering this amount of time as their typical sun exposure (Table 7). This finding could be attributed to an actual increase in sun exposure from Visit 1 to Visit 2 with participants spending more 
time outside during the summer, and that Visit 1 followed spring, a rainy season for the central coast. Although the 28-day sun exposure recall questionnaire did not capture a significant difference between visits, the FLASH Questionnaire provided helpful insight to suggest an increase in sun exposure during Visit 2. It is likely that the 28-day recall questionnaire did not sufficiently capture the participant's sun exposure after their summer break (Visit 2) because the questionnaire was not long enough. Future studies should include a question specific to the participant's summer schedule and vacations. Dawson-Hughes, Harris \& Dallal (1997) compared participant's serum 25(OH)D levels relative to the season, travel during the year and dietary vitamin $D$ intake. Participants taking vacations with tropical sun exposure (latitudes $\leq 35^{\circ} \mathrm{N}$ ) reduced the seasonal variation of serum $25(\mathrm{OH}) \mathrm{D}$ levels during the winter months (DawsonHughes, Harris \& Dallal, 1997). Therefore, future studies should track each participant's summer location and vacations, especially considering that none of the models in Visit 2 significantly predicted serum 25(OH)D status. There may have also been a saturation of $25(\mathrm{OH}) \mathrm{D}$ after summer sun exposure which contributed to the insignificant findings with the predictive models for Visit 2. Administering a questionnaire and blood draw during the summertime could help to explain this phenomenon in future research studies.

Overall, the strongest predictors of serum $25(\mathrm{OH}) \mathrm{D}$ were weekend sun exposure (categorical), fish intake (categorical) and forehead skin reflectance $\left(R^{2}=0.50, p=0.0010\right.$, Table 9) for Visit 1 . The SEl (11am-3pm) was also found to be a stronger predictor of serum $25(\mathrm{OH}) \mathrm{D}$ status than the entire day $(7 \mathrm{am}-7 \mathrm{pm})$ 
(Table 9). Categorical weekend sun exposure was reported to be higher (Table 9) and was a stronger predictor than weekday sun exposure (data not shown). Participants may have underestimated their weekday sun exposure through the inaccurate recall of their daily activities, such as the amount of time spent in the sun walking to and from destinations (i.e. their classes, the dorms, etc). Although milk intake was not a significant predictor of status, categorical fish intake was a better predictor of vitamin $D$ status than the 28-day vitamin $D$ specific food frequency recall questionnaire (Table 9). Focusing on weekend sun exposure and fish intake, both potentially concentrated sources of vitamin $D$, in future research is suggested.

Variables that did not significantly predict serum 25(OH)D in the full model were race/ethnicity, maternal/paternal education, maternal/paternal income level, age, BMI, BSA, gender and sunscreen use. Contrary to the present study, Kant and Graubard (2007) found significant differences in vitamin D intake and serum 25(OH)D by race/ethnicity. They used data from NHANES III and NHANES 1999-2002 to compare vitamin D intake and vitamin D status in Mexican Americans, non-Hispanic whites and non-Hispanic Blacks (Kant \& Graubard, 2007). They found that concentrations of $25(\mathrm{OH}) \mathrm{D}<37.5 \mathrm{nmol} / \mathrm{L}$ (inadequate) were more likely among non-Hispanic blacks and Mexican Americans than nonHispanic whites, while non-Hispanic whites had the highest intakes of vitamin D. Kant and Graubard (2007) used a logistic regression model and found that race/ethnicity was a strong independent predictor of dietary vitamin $D$ intake and serum 25(OH)D, once accounting for income and education level (Kant \& 
Graubard, 2007). They concluded that skin pigmentation and race/ethnicity is an important factor to consider due to the differences in behavior and genetics (Kant \& Graubard, 2007). Race/ethnicity was not significant in the present study likely because the subpopulation included a homogeneous group of participants with similar demographics. To ensure the results were not due to insufficient number of participants or the inability to test for interpersonal variability, future studies should include a larger more heterogeneous sample.

The strengths of the present study include multiple assessment tools used to analyze dietary vitamin $\mathrm{D}$ intake and sun exposure as well as the longitudinal nature of the study in which participants were tracked over time to document winter (during spring) and summer (during fall) sun exposure. Limitations include a small sample size, the amount of attrition and inherent limitations of the recall questionnaires and online questionnaires. Attrition may be attributable to various factors. Two of the participants did not return to Cal Poly their sophomore year of college, while six of the students who enrolled in the vitamin D study did not wish to participate in the second assessment. Keeping in touch with participants over the summer break could potentially help with attrition. Inherent limitations of the FFQ include a recall bias that is often accompanied with the non structured schedule/ meal patterns of many college students. Do to the variability in meal planning, timing and options during the school year (Visit 1) a greater challenge is posed for accurate recall data. The variability and inconsistency of summer schedule (Visit 2) also increases the likelihood of a recall bias and inaccurate data. Food frequency questionnaires (FFQ) and diet histories are based on the 
individual's perceptions of usual intake which relies on the participant's memory. Recommendations for future studies would include a highly trained interviewer to obtain accurate data.

The FLASH Vitamin D study hypothesized sun exposure recall questionnaires, food frequency questionnaires specific to vitamin $D$ intake and skin reflectance measurements would predict individual serum 25(OH)D status. This study demonstrated the accuracy of simple tools when accessing the contribution of sun exposure, skin reflectance and vitamin D intake to the participants' vitamin D status. The study found that $90 \%$ of the participants in the spring and $88 \%$ in the fall did not achieve the RDA level of intake (600 IU/day) for vitamin $\mathrm{D}$, and yet only $5 \%$ of the participants in spring and none in the fall were below the recommended serum 25(OH)D level of $<50 \mathrm{nmol} / \mathrm{L}$. Serum 25(OH)D levels increased from the spring to fall visit, however, vitamin D intake did not increase while frequency of sun exposure increased. This finding helps to demonstrate the large contribution sun exposure has to vitamin D status. The most significant predictors of serum $25(\mathrm{OH}) \mathrm{D}$ in this study were the participants' weekend sun exposure, fish intake and average forehead skin reflectance $\left(R^{2}=\right.$ $0.50, p=0.0010)$ as captured using simple methods. Thus, the variables that significantly predicted serum 25(OH)D status may be assessed using nonburdensome tools and recall questionnaires in future studies.

Ideally this study's data will help us better understand how to predict and access the most accurate contributors to vitamin $D$ status. Although vitamin $D$ is uniquely synthesized from exposure to sunlight, there are no current public 
health recommendations or guidelines for sun exposure which may be the most economical solution to the vitamin D deficiency seen in other parts of the United States (IOM, 2010) and worldwide (Bueno \& Czepielewski, 2008). 


\section{Bibliography}

Armas, L., Dowell, S., Akhter, M., et al. (2007). Ultraviolet-B radiation increases serum 25-hydroxyvitamin D levels: the effect of UVB dose and skin color. J Am Acad Dermatol;57:588-93.

Bang, H. (2009). New York- Presbyterian Hospital/Weill Cornell Medical Center/Weill Cornell Medical College (2009, March 12). One In Seven U.S. Teens Is Vitamin D Deficient. ScienceDaily. Retrieved August 2, 2011, from http://www.sciencedaily.com releases/2009/03/090311124028.htm

Barger-Lux, M. \& Heaney R. (2002). Effects of above average summer sun exposure on serum 25-hydroxyvitamin $\mathrm{D}$ and calcium absorption. J Clin Endocrinol Metab. 2002;87:4952-6.

Bikle, D. (2007). What is new in vitamin D: Curr Opin Rheumatol. 2007;19:383-8.

Boscoe, F \& Schymura, M. (2006). Solar ultraviolet-B exposure and cancer incidence and mortality in the United States. BMC Cancer. 6:264.

Bueno, A. \& Czepielewski, M. (2008). The importance for growth of dietary intake of calcium and vitamin D. Jornal de Pediatria. 84(5):386394.

Centers for Disease Control and Prevention. (2010). Obesity and Overweight. Retrieved from http://www.cdc.gov/obesity/data/trends.html.

Centers for Disease Control and Prevention. (2011). NHANES Data. Retrieved from http://www.cdc.gov/nchs/nhanes.htm.

Cummings, S. \& Melton, L. (2002). Epidemiology and outcomes of osteoporotic fractures. Lancet 359:1761.

Dawson-Hughes, B., Harris, S. \& Dallal, G. (1997) Plasma calcidiol, season, and serum parathyroid hormone concentrations in healthy elderly men and women. Am J Clin Nutr. 65:67-71.

Dawson-Hughes, B., Heaney, R., Holick, M., Lips, P., Meunier, P. \& Vieth R. (2005). Estimates of optimal vitamin D status. Osteoporos Int. 16:7136.

DeLuca, H. (2004). Overview of general physiologic features and functions of vitamin D. Am J Clin Nutr. 80:1689S-96S.

Dobnig, H., Pilz, S., Scharnagl, H., et al. (2008). Independent association of low 
serum 25-hydroxyvitamin $d$ and 1,25-dihydroxyvitamin d levels with allcause and cardiovascular mortality. Arch Intern Med. 168:1340-9.

Food and Nutrition Information Center. (2011). Dietary Guidance: Vitamin D. Retrieved from http://fnic.nal.usda.gov.

Garabedian, M., \& Ben-Mekhbi, H. (1999). Rickets and vitamin D deficiency. In Vitamin D physiology, molecular biology, and clinical applications. 273286.

Garland, C., Gorham, E., Mohr, S. et al. (2007). Vitamin D and prevention of breast cancer: pooled analysis. J Steroid Biochem Mol Biol. 103:708-11.

Giovannucci, E., Liu, Y. \& Rimm, E. et al. (2006). Prospective study of predictors of vitamin $D$ status and cancer incidence and mortality in men. $J$ Natl Cancer Inst. 98:451-9.

Haddad, J., Matsuoka, L., Hollis, B., Hu, Y. \& Wortsman, J. (1993). Human plasma transport of vitamin $\mathrm{D}$ after its endogenous synthesis. $J$ Clin Invest. 91:2552-5.

Hall, L., Kimlin, M., Aronov, P., Hammock, B., Slusser, J., Woodhouse, \& Stephensen, C. (2010). Vitamin D Intake Needed to Maintain Target Serum 25-Hydroxyvitamin D Concentrations in Participants with Low Sun Exposure and Dark Skin Pigmentation Is Substantially Higher Than Current Recommendations. J Clin Invest.10.3945/jn.109.115253.

Hall, L. (2008). Sun Exposure, Skin Reflectance and Vitamin D Intake to Predict Vitamin D Status. Dissertation, University of California Davis. UMI 3350731.

Heaney, R. (2007) Bone health. Am J Clin Nutr. 85:300S-303S.

Heaney, R. (2008). Vitamin D in health and disease. Clin J Am Soc Nephrol. 3:1535-41.

Holick, M. (2006a). Resurrection of vitamin D deficiency and rickets. J Clin Invest. 116:2062-72.

Holick, M. (2004a). Sunlight and vitamin D for bone health and prevention of autoimmune diseases, cancers, and cardiovascular disease. American Journal of Clinical Nutrition, Vol. 80, No. 6, 1678S-1688S.

Holick, M. (2006b). Vitamin D deficiency in obesity and health consequences. Current Opinion in Endocrinology, Diabetes and Obesity. 13:121. 
Holick, M. (2003). Vitamin D: A millenium perspective. J Cell Biochem. 88:296307.

Holick, M. (2004b). Vitamin D: importance in the prevention of cancers, type 1 diabetes, heart disease, and osteoporosis. Am J Clin Nutr. 79:362-71.

Holick, M. (2002) Vitamin D: the underappreciated D-lightful hormone that is important for skeletal and cellular health. Curr Opin Endocrinol Diabetes. 9:87-98.

Holick, M., MacLaughlin, J. \& Doppelt, S. (1981). Factors that Influence the Cutaneous Photosynthesis of Previtamin $D_{3}$. Science. 211:590-593.

Hypponen, E. \&Power, C. (2007). Hypovitaminosis D in British adults at age 45 y: nationwide cohort study of dietary and lifestyle predictors. Am J Clin Nutr. 85:860-8.

International Osteoporosis Foundation. (2010). Facts and Statistics for Osteoporisis. Retrieved from http://www.iofbonehealth.org/about-iof.html.

Institute of Medicine, Food and Nutrition Board. (2009). Dietary Reference Intakes for Vitamin D and Calcium. Version current 9/14/09. Retrieved from http://www.iom.edu/CMS/3788/61170.aspx

Kant, A. \& Graubard, B. (2007). Ethnicity is an independent correlate of biomarkers of micronutrient intake and status in American adults. $J$ Nutr;137:2456-63.

Looker, A., Johnson, C., Lacher, D., Pfeiffer, C., Schleicher, R. \& Sempos, C. (2011). Vitamin D Status in the United States. NCHS Data Brief. No. 29. March 2011.

MacLaughlin, J., Anderson, R. \& Holick, M. (1982). Spectral character of sunlight modulates photosynthesis of previtamin D3 and its photoisomers in human skin. Science. 216:1001-3.

Matsuoka, L., Wortsman, J., Dannenberg, M., Hollis, B., Lu, Z. \& Holick, M. (1992). Clothing prevents ultraviolet-B radiation-dependent photosynthesis of vitamin D3. J Clin Endocrinol Metab. 75:1099-103.

Matsuoka, L. Wortsman, J., Haddad, J., Kolm, P. \& Hollis, B. (1991). Racial pigmentation and the cutaneous synthesis of vitamin D. Arch Dermatol. 127:536-8. 
Mellanby, E. (1919). An experimental investigation on rickets. Nutrition. 1989; 5:81-6; discussion 87.

Moore, C., Murphy, M. \& Holick, M. (2012). Vitamin D Intakes by Children and Adults in the United States Differ among Ethnic Groups. The Journal of Nutrition. 135.10.2478.

Nordin \& Morris. (1994). Journal of Cellular Chemistry Volume 49, Issue 1; pages 19-25. DOI: 10.1002/jcb.240490105.

Office of Dietary Supplements National Institutes of Health. (2009). Dietary supplement fact sheet: Vitamin D. Version current 9/11/09. Retrieved from http://ods.od.nih.gov/factsheets/vitamind.asp

Ponsonby, A., McMichael, A. \& van der Mei, I. (2002). Ultraviolet radiation and autoimmune disease: insights from epidemiological research. Toxicology. 181-182:71-78.

Prentice A, Goldberg G. \& Schoenmakers, I. (2008). Vitamin D across the lifecycle: physiology and biomarkers. Am J Clin Nutr. 88:500S-6S.

Rajakumar, K (2003). Vitamin D, Cod- Liver Oil, and Rickets: A Historical Perspective. Am J Pediatr. Vol. 112 No. 2: 132 -135.

Ross, C., Taylor, C., Yaktine, A. \& Del Valle, H. (2010). Dietary Reference Intake for Calcium and Vitamin D. Institute of Medicine. http://www.nap.edu/catalog/13050.html.

Shah, B. \& Finberg, L. (1994). Single-dose therapy for nutritional vitamin D deficiency rickets: a preferred method. J. Pediatr. 125:487-490.

Suda, T., Ueno, Y., Fujii, K. \& Shinki, T. (2002). Vitamin D and bone. J Cell Biochem. 88:259-66.

Sullivan, S., Cobb, J., Rosen, C., Holick, M., Chen, T., Kimlin, M. \& Parisi, A. (2003).Assessment of sun exposure in adolescent girls using activity diaries. Nutrition Research. 2003;23:631-644.

van der Meer, I., Boeke, A., Lips, P. et al. (2008). Fatty fish and supplements are the greatest modifiable contributors to the serum 25hydroxyvitamin D concentration in a multiethnic population. Clin Endocrinol. 68:466-72.

Wagner, C. \& Greer, F. (2008). American Academy of Pediatrics Section 
on Breastfeeding; American Academy of Pediatrics Committee on Nutrition. Prevention of rickets and vitamin $D$ deficiency in infants, children, and adolescents. Pediatrics.122:1142-1152.

Wang, A.Y., Lam, C.W., \& Sanderson, J.E. et al. (2008). Serum 25hydroxyvitamin $\mathrm{D}$ status and cardiovascular outcomes in chronic peritoneal dialysis patients: a 3-y prospective cohort study. Am J Clin Nutr. 87:1631-8.

Webb, A. (2006). Who, what, where and when-influences on cutaneous vitamin D synthesis. Prog Biophys Mol Biol;92:17-25.

Webb, A., Pilbeam, C., Hanafin, N. \& Holick, M. (1990). An evaluation of the relative contributions of exposure to sunlight and of diet to the circulating concentrations of 25-hydroxyvitamin $D$ in an elderly nursing home population in Boston. Am J Clin Nutr. 51:1075-81.

Wortsman, J., Matsuoka, L., Chen, T., Lu, Z. \& Holick, M. (2000).

Decreased bioavailability of vitamin D in obesity. Am J Clin Nutr. 72:690-3.

Zella, J. \& DeLuca, H. (2003). Vitamin D and autoimmune diabetes. J Cell Biochem. 88:216-22.

Zitterman. (2003) Low vitamin D status: a contributing factor in the pathogenesis of congestive heart failure? Am Coll Cardiol. 41:105-112. 